\title{
Impacts of updated spectroscopy on thermal infrared retrievals of methane evaluated with HIPPO data
}

\author{
M. J. Alvarado ${ }^{1}$, V. H. Payne ${ }^{2}$, K. E. Cady-Pereira ${ }^{1}$, J. D. Hegarty ${ }^{1}$, S. S. Kulawik ${ }^{3}$, K. J. Wecht ${ }^{4}$, J. R. Worden ${ }^{2}$, \\ J. V. Pittman ${ }^{5}$, and S. C. Wofsy ${ }^{5}$ \\ ${ }^{1}$ Atmospheric and Environmental Research, Lexington, MA, USA \\ ${ }^{2}$ Jet Propulsion Laboratory, California Institute of Technology, Pasadena, CA, USA \\ ${ }^{3}$ Bay Area Environmental Research Institute, Mountain View, CA, USA \\ ${ }^{4}$ School of Engineering and Applied Science, Harvard University, Cambridge, MA, USA \\ ${ }^{5}$ Department of Earth and Planetary Sciences, Harvard University, Cambridge, MA, USA
}

Correspondence to: M. J. Alvarado (malvarad@aer.com)

Received: 12 August 2014 - Published in Atmos. Meas. Tech. Discuss.: 29 September 2014

Revised: 29 January 2015 - Accepted: 3 February 2015 - Published: 27 February 2015

\begin{abstract}
Errors in the spectroscopic parameters used in the forward radiative transfer model can introduce spatially, temporally, and altitude-dependent biases in trace gas retrievals. For well-mixed trace gases such as methane, where the variability of tropospheric mixing ratios is relatively small, reducing such biases is particularly important. We use aircraft observations from all five missions of the HIAPER Pole-toPole Observations (HIPPO) of the Carbon Cycle and Greenhouse Gases Study to evaluate the impact of updates to spectroscopic parameters for methane $\left(\mathrm{CH}_{4}\right)$, water vapor $\left(\mathrm{H}_{2} \mathrm{O}\right)$, and nitrous oxide $\left(\mathrm{N}_{2} \mathrm{O}\right)$ on thermal infrared retrievals of methane from the NASA Aura Tropospheric Emission Spectrometer (TES). We find that updates to the spectroscopic parameters for $\mathrm{CH}_{4}$ result in a substantially smaller mean bias in the retrieved $\mathrm{CH}_{4}$ when compared with HIPPO observations. After an $\mathrm{N}_{2} \mathrm{O}$-based correction, the bias in TES methane upper tropospheric representative values for measurements between $50^{\circ} \mathrm{S}$ and $50^{\circ} \mathrm{N}$ decreases from 56.9 to $25.7 \mathrm{ppbv}$, while the bias in the lower tropospheric representative value increases only slightly (from 27.3 to $28.4 \mathrm{ppbv}$ ). For retrievals with less than 1.6 degrees of freedom for signal (DOFS), the bias is reduced from 26.8 to $4.8 \mathrm{ppbv}$. We also find that updates to the spectroscopic parameters for $\mathrm{N}_{2} \mathrm{O}$ reduce the errors in the retrieved $\mathrm{N}_{2} \mathrm{O}$ profile.
\end{abstract}

\section{Introduction}

Methane $\left(\mathrm{CH}_{4}\right)$ is an important greenhouse gas (GHG), a critical component of the Earth's carbon cycle, and a source of background tropospheric $\mathrm{O}_{3}$ (Ciais et al., 2013; Myhre et al., 2013). Globally averaged surface concentrations of $\mathrm{CH}_{4}$ have risen from $722 \pm 25 \mathrm{ppb}$ in 1750 to $1803 \pm 2 \mathrm{ppb}$ by 2011 (Myhre et al., 2013), primarily due to increased anthropogenic emissions of $\mathrm{CH}_{4}$. While $\mathrm{CH}_{4}$ concentrations appeared to stabilize in 1999 (Rigby et al., 2008), they began increasing again in 2007 (Dlugokencky et al., 2011) and the sources of this renewed increase are not yet clear. Cutting anthropogenic $\mathrm{CH}_{4}$ emissions has been identified as one of the most efficient methods to mitigate the radiative forcing of GHGs on decadal time scales due to the strong warming potential of $\mathrm{CH}_{4}$ (86 times higher than $\mathrm{CO}_{2}$ on a 20 -year time horizon, Myhre et al., 2013) and the relatively short lifetime of $\mathrm{CH}_{4}$ in the atmosphere $(9.14$ years $\pm 10 \%$, Ciais et al., 2013). Quantifying the anthropogenic and natural emissions of $\mathrm{CH}_{4}$ is thus essential to determining $\mathrm{CH}_{4}$ emission reduction targets and verifying that these targets have been met. Atmospheric observations can provide "top-down" constraints to improve the bottom-up $\mathrm{CH}_{4}$ emission inventories (Weiss and Prinn, 2011). Satellite observations can provide global, spatially and temporally dense data covering many years, and are therefore extremely valuable to these topdown studies. Methane retrievals from measurements of solar backscatter in the shortwave infrared (SWIR) have been used to provide data on the spatial distribution of $\mathrm{CH}_{4}$ (e.g., 
Bergamaschi et al., 2007, 2009; Frankenberg et al., 2011; Meirink et al., 2008). The SWIR retrievals are sensitive to the entire tropospheric column but their dependence on reflected sunlight precludes observations at night, over most ocean surfaces, and over most cloudy targets. Measurements of terrestrial radiation in the thermal infrared (TIR) have also been utilized to study the emissions and transport of $\mathrm{CH}_{4}$ (e.g., Worden et al., 2013a, b; Crevoisier et al., 2009, 2013; Massart et al., 2014; Razavi et al., 2009; Xiong et al., 2008, 2009, 2010). TIR retrievals have limited sensitivity to the lower troposphere but can be performed day and night, over land and ocean, and for partly cloudy scenes. In recent years, there has been interest in utilization of TIR measurements together with SWIR measurements in order to separate boundary layer and free tropospheric contributions to the methane columns (Herbin et al., 2013). Minimizing retrieval biases in both the TIR and SWIR retrievals are a critical factor in the success of these efforts.

The Tropospheric Emission Spectrometer (TES), flying on the Aura satellite, measures TIR radiances, including the $8 \mu \mathrm{m} \mathrm{CH}_{4}$ region. The high spectral resolution of the TES instrument $\left(0.06 \mathrm{~cm}^{-1}\right)$ allows it to separate the signals from interfering species more easily than other satellitebased nadir TIR sounders, and TES can therefore provide additional insight into retrieval biases from these instruments. In this paper, we evaluate the impact of recent updates to the spectroscopic parameters in Version 6 (V006) of the TES retrieval products on the retrieved profile of $\mathrm{CH}_{4}$. In addition, we evaluate the impact of proposed updates to the $\mathrm{N}_{2} \mathrm{O}$ spectroscopic parameters in the forward model of the TES retrieval algorithm on the retrieved $\mathrm{CH}_{4}$. We perform these validations using the extensive set of vertical profiles of $\mathrm{CH}_{4}$ measured from aircraft by the five campaigns of the HIAPER Pole-to-Pole Observations (HIPPO) of Carbon Cycle and Greenhouse Gases Study over the Pacific (Wofsy et al., 2011). This evaluation follows the methods of Wecht et al. (2012), but differs from that previous study in the following ways: (a) we are evaluating the performance of the upcoming TES Version 6 products, whereas Wecht et al. (2012) evaluated the TES Version 4 and 5 products; (b) we use all five HIPPO campaigns, whereas Wecht et al. (2012) only had access to data from the first two HIPPO campaigns; (c) we examine the spectral residuals as part of the evaluation. We characterize the errors in individual profiles and the mean biases, and the variability of these mean biases with latitude and height. We also illustrate the impact of two postretrieval bias-correction algorithms on the TES $\mathrm{CH}_{4}$ products: the $\mathrm{N}_{2} \mathrm{O}$-based correction of Worden et al. (2012) and a global bias correction based on the results of this validation study.

Section 2 describes the TES and HIPPO measurements. Section 3 describes the TES $\mathrm{CH}_{4}$ retrieval algorithm, including the changes to spectroscopic parameters. This section also describes updates to the a priori profiles for the version being evaluated in this study, although these are shown to have a minor impact on the retrieval results. Section 4 describes the methodology of our validation study. Sections 5 and 6 present the results for TES Version 6 and the proposed updates to the $\mathrm{N}_{2} \mathrm{O}$ spectroscopic parameters, respectively.

\section{Data}

\subsection{TES}

TES is a nadir-viewing Fourier-transform infrared (FTIR) spectrometer aboard the NASA Aura spacecraft (Beer et al., 2001). Aura is in a sun-synchronous orbit that repeats every 16 days with daytime and nighttime overpasses at 13:30 and 01:30 (mean local solar time). TES Global Survey observations are about $180 \mathrm{~km}$ apart along the orbit track, while special observation modes, such as Step \& Stare and Transect, can be used for increased spatial sampling (generally 45 and $12 \mathrm{~km}$, respectively) over specific regions. TES's high spectral resolution $\left(0.06 \mathrm{~cm}^{-1}\right)$, spatial resolution $\left(5 \times 8 \mathrm{~km}^{2}\right)$, and radiometric stability (Connor et al., 2011) provide the capacity to measure atmospheric concentrations of many gas species, including $\mathrm{O}_{3}$ (Worden et al., 2007; Nassar et al., 2008), CO (Rinsland et al., 2006; Luo et al., 2007), $\mathrm{CH}_{4}$ (Worden et al., 2012, 2013a, b; Wecht et al., 2012), $\mathrm{CO}_{2}$ (Kulawik et al., 2010, 2013), HDO (Worden et al., 2012), $\mathrm{NH}_{3}$ (Shephard et al., 2011; Zhu et al., 2013; Pinder et al., 2011), $\mathrm{CH}_{3} \mathrm{OH}$ (Cady-Pereira et al., 2012; Wells et al., 2012), HCOOH (Cady-Pereira et al., 2014), OCS (Kuai et al., 2014), and PAN (Alvarado et al., 2011; Payne et al., 2014).

\subsection{HIPPO}

Measurements from the HIPPO aircraft campaigns provide an excellent data set for satellite validation, due to the large number of measurements, the extensive latitudinal coverage, and the vertical extent of the profiles (up to $14 \mathrm{~km}$ for some cases). Figure 1 shows the flight paths of the NSF's Gulfstream V (GV) during the five HIPPO missions (HIPPO I in January 2009; HIPPO II in October-November 2009; HIPPO III in March-April 2010; HIPPO IV in JuneJuly 2011; and HIPPO V in August-September 2011). The $\mathrm{GV}$ transected the Pacific Ocean from $87^{\circ} \mathrm{N}$ to $67^{\circ} \mathrm{S}$, performing vertical profiles every $\sim 220 \mathrm{~km}$ or $20 \mathrm{~min}$ (Wofsy et al., 2011, 2012). $\mathrm{CH}_{4}$ was measured with a quantum cascade laser spectrometer (QCLS) at $1 \mathrm{~Hz}$ frequency with accuracy of $1.0 \mathrm{ppb}$ and precision of $0.5 \mathrm{ppb}$ (Kort et al., 2011). HIPPO $\mathrm{CH}_{4}$ data are reported on the NOAA calibration scale and have been used in several other studies to evaluate satellite retrievals of $\mathrm{CH}_{4}$ (e.g., Wecht et al., 2012; Crevoisier et al., 2013; Massart et al., 2014). Comparisons with flask data from the NOAA Whole Air Sampler (NWAS) showed a mean positive bias of $0.85 \mathrm{ppb}$ for the QCLS measurements against the NOAA flask data during the HIPPO campaigns, which is consistent with the estimated QCLS accuracy of $1.0 \mathrm{ppb}$ (Santoni et al., 2014). 
(a) Flight Tracks for HIPPO I

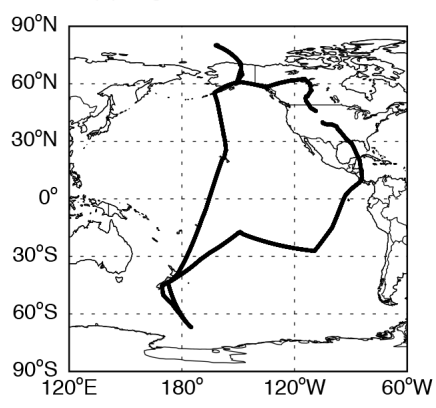

(d) Flight Tracks for HIPPO IV

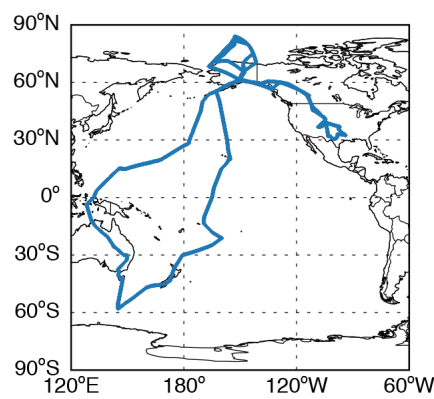

(b) Flight Tracks for HIPPO II

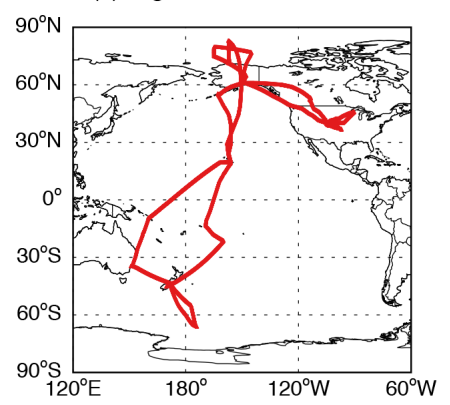

(c) Flight Tracks for HIPPO III

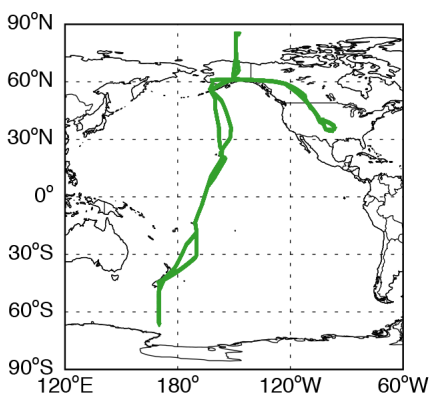

(e) Flight Tracks for HIPPO V

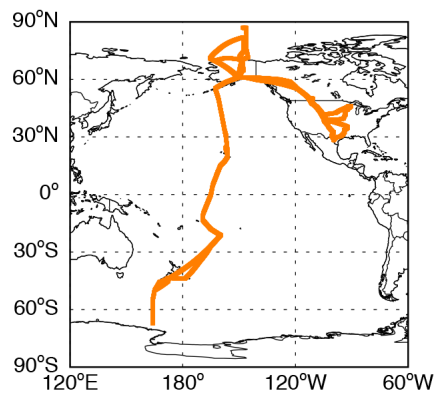

Figure 1. Flight tracks for HIPPO campaigns I through V.

\section{$3 \quad \mathrm{TES} \mathrm{CH}_{4}$ retrieval algorithm}

TES retrievals of trace gas profiles are based on an optimal estimation approach (with a priori constraints, e.g., Rodgers, 2000; Bowman et al., 2006) that minimizes the differences between the TES Level 1B spectral radiances $\mathbf{L}$ and a radiative transfer calculation that uses absorption coefficients calculated with the line-by-line radiative transfer model LBLRTM (Clough et al., 2005, 2006). That is, the algorithm solves for the state vector $\boldsymbol{x}$ that minimizes the cost function:

$$
J=[\mathbf{L}-\boldsymbol{F}(\boldsymbol{x})]^{-T} \mathbf{S}_{\mathrm{m}}^{-1}[\mathbf{L}-\boldsymbol{F}(\boldsymbol{x})]+\left[\boldsymbol{x}-\boldsymbol{x}^{a}\right]^{T} \mathbf{S}_{a}^{-1}\left[\boldsymbol{x}-\boldsymbol{x}^{a}\right],
$$

where $\boldsymbol{F}(\boldsymbol{x})$ is the non-linear radiative transfer calculation (also called the "forward model") that relates the state vector to the calculated radiances, $\mathbf{S}_{\mathrm{m}}$ is the covariance of the measurement noise, $\boldsymbol{x}^{a}$ is the a priori value of the state vector, and $\mathbf{S}_{a}^{-1}$ is the "constraint matrix", generally the inverse of the covariance of a prior climatology of $\boldsymbol{x}$.

The $\mathrm{CH}_{4}$ retrieval algorithm for TES Version 5 is described in detail in Worden et al. (2012), and the same basic approach is used in TES Version 6. In this approach, joint estimates of $\mathrm{H}_{2} \mathrm{O}, \mathrm{HDO}, \mathrm{CH}_{4}$, and $\mathrm{N}_{2} \mathrm{O}$ are retrieved simultaneously from TES radiances covering the spectral region between 1100 and $1330 \mathrm{~cm}^{-1}$ with the exception of a $10 \mathrm{~cm}^{-1}$ wide region centered at 1280 and a $2 \mathrm{~cm}^{-1}$ wide region centered at $1308 \mathrm{~cm}^{-1}$, which contain a strong CFC absorption feature and the $\mathrm{CH}_{4} \mathrm{Q}$ branch, respectively. The state vector for the joint estimate is

$$
\boldsymbol{x}=\left[\begin{array}{c}
\boldsymbol{x}_{\mathrm{H}_{2} \mathrm{O}} \\
\boldsymbol{x}_{\mathrm{HDO}} \\
\boldsymbol{x}_{\mathrm{CH}_{4}} \\
\boldsymbol{x}_{\mathrm{N}_{2} \mathrm{O}} \\
T_{\text {surf }} \\
P_{\text {cloud }} \\
\tau_{\text {cloud }}
\end{array}\right]=\mathbf{M}\left[\begin{array}{c}
z_{\mathrm{H}_{2} \mathrm{O}} \\
\boldsymbol{z}_{\mathrm{HDO}} \\
z_{\mathrm{CH}_{4}} \\
z_{\mathrm{N}_{2} \mathrm{O}} \\
T_{\text {surf }} \\
P_{\text {cloud }} \\
\tau_{\text {cloud }}
\end{array}\right],
$$

where the column vectors $\boldsymbol{x}_{i}$ are the natural logarithms of the volume mixing ratios (VMRs) of the various retrieved species on the 67 level pressure grid from 1000 to $0.1 \mathrm{hPa}$ used in the TES forward model. Updated estimates of surface temperature $\left(T_{\text {surf }}\right)$, cloud pressure $\left(P_{\text {cloud }}\right)$, and cloud effective optical depth $\left(\tau_{\text {cloud }}\right)$ are also retrieved. The atmospheric species are actually retrieved on subsets of this grid (the levels of the vectors $z$ in Eq. 2), related to the forward model grid by the mapping matrix $\mathbf{M}$, but for the sake of brevity we exclude this mapping in subsequent equations.

The retrieved $\mathrm{CH}_{4}$ profile $\hat{\boldsymbol{x}}_{\mathrm{CH}_{4}}$ is related to the true profile $\boldsymbol{x}_{\mathrm{CH}_{4}}$ by the equation (Worden et al., 2012):

$$
\begin{aligned}
\hat{\boldsymbol{x}}_{\mathrm{CH}_{4}}= & \boldsymbol{x}_{\mathrm{CH}_{4}}^{a}+\mathbf{A}_{\mathrm{cc}}\left(\boldsymbol{x}_{\mathrm{CH}_{4}}-\boldsymbol{x}_{\mathrm{CH}_{4}}^{a}\right)+\mathbf{A}_{\mathrm{cn}}\left(\boldsymbol{x}_{\mathrm{N}_{2} \mathrm{O}}-\boldsymbol{x}_{\mathrm{N}_{2} \mathrm{O}}^{a}\right) \\
& +\mathbf{A}_{\mathrm{cj}}\left(\boldsymbol{x}_{j}-\boldsymbol{x}_{j}^{a}\right)+\mathbf{G}_{c} \mathbf{K}_{b}\left(\boldsymbol{b}-\boldsymbol{b}^{a}\right)+\mathbf{G}_{c} \boldsymbol{n},
\end{aligned}
$$


where $\mathbf{A}_{\mathrm{cc}}$ is the averaging kernel matrix describing the sensitivity of the retrieved $\mathrm{CH}_{4}$ profile to the true state: $\mathbf{A}_{\mathrm{cc}}=$ $\frac{\partial \hat{\boldsymbol{x}}_{\mathrm{CH}_{4}}}{\partial \boldsymbol{x}_{\mathrm{CH}_{4}}} \cdot \mathbf{A}_{\mathrm{cn}}$ and $\mathbf{A}_{\mathrm{cj}}$ are the sensitivity of $\hat{\boldsymbol{x}}_{\mathrm{CH}_{4}}$ to the jointly retrieved $\mathrm{N}_{2} \mathrm{O}$ profile and all other jointly retrieved parameters, respectively. $\mathbf{K}_{b}=\frac{\partial \mathbf{L}}{\partial \boldsymbol{b}}$ is the partial-derivative (i.e., Jacobian) matrix of the sensitivity of the radiances to unretrieved model parameters $\boldsymbol{b}$. The vector $\boldsymbol{n}$ is the noise in the radiance measurement as a function of wavelength, while $\mathbf{G}_{c}$ is the gain matrix, or the sensitivity of $\hat{\boldsymbol{x}}_{\mathrm{CH}_{4}}$ to the radiance:

$\mathbf{G}_{c}=\frac{\partial \hat{\boldsymbol{x}}_{\mathrm{CH}_{4}}}{\partial \mathbf{L}}=\left(\mathbf{K}_{c}^{T} \mathbf{S}_{\mathrm{m}}^{-\mathbf{1}} \mathbf{K}_{c}+\mathbf{S}_{a}^{-\mathbf{1}}\right)^{-1} \mathbf{K}_{c}^{T} \mathbf{S}_{\mathrm{m}}^{-1}$,

where $\mathbf{K}_{c}=\frac{\partial \mathbf{L}}{\partial \boldsymbol{x}_{\mathrm{CH}_{4}}}$ is the sensitivity of the radiances to changes in the true state of $\mathrm{CH}_{4}$, and $\mathbf{S}_{a}^{-1}$ is the $\mathrm{CH}_{4}$ constraint matrix, which is derived as the inverse of the covariance of a set of $\mathrm{CH}_{4}$ profiles from version 4 of the Whole Atmosphere Community Climate Model (WACCM, Marsh et al., 2013), modified based on knowledge gained from in situ and satellite observations (Kulawik et al., 2006; Worden et al., 2011, 2012).

The raw retrieved $\mathrm{CH}_{4}$ profile from TES $\left(\hat{\boldsymbol{x}}_{\mathrm{CH}_{4}}\right)$ can have a significant positive bias due to errors in unretrieved model parameters $(\boldsymbol{b})$ such as the temperature profile, surface emissivity, and spectroscopic parameters. Worden et al. (2012) assumed that (1) errors that affect the retrieved profile of $\mathrm{N}_{2} \mathrm{O}$ will have a similar effect on $\mathrm{CH}_{4}$ and that (2) all deviations of the retrieved $\mathrm{N}_{2} \mathrm{O}$ from the a priori profile are due to systematic errors (e.g., errors in the temperature profile, surface temperature, clouds, and surface emissivity). Thus the retrieved $\mathrm{N}_{2} \mathrm{O}$ profile is used to adjust the $\mathrm{CH}_{4}$ profile via the equation:

$\hat{\boldsymbol{x}}_{\mathrm{CH}_{4}}^{\text {adj }}=\hat{\boldsymbol{x}}_{\mathrm{CH}_{4}}-\hat{\boldsymbol{x}}_{\mathrm{N}_{2} \mathrm{O}}+\boldsymbol{x}_{\mathrm{N}_{2} \mathrm{O}}^{a}$.

The idea of this $\mathrm{N}_{2} \mathrm{O}$ correction is similar to the use of $\mathrm{CO}_{2}$ in "proxy" retrievals of $\mathrm{CH}_{4}$ from SWIR measurements (Frankenberg et al., 2005). The $\mathrm{N}_{2} \mathrm{O}$-corrected $\mathrm{CH}_{4}$ profile $\hat{\boldsymbol{x}}_{\mathrm{CH}_{4}}{ }^{\text {adj }}$ is then related to the true profile by the following equation (Worden et al., 2012):

$$
\begin{aligned}
\hat{\boldsymbol{x}}_{\mathrm{CH}_{4}}^{\mathrm{adj}} & =\boldsymbol{x}_{\mathrm{CH}_{4}}^{a}+\left(\mathbf{A}_{\mathrm{cc}}-\mathbf{A}_{\mathrm{nc}}\right)\left(\boldsymbol{x}_{\mathrm{CH}_{4}}-\boldsymbol{x}_{\mathrm{CH}_{4}}^{a}\right) \\
& -\left(\mathbf{A}_{\mathrm{nn}}-\mathbf{A}_{\mathrm{cn}}\right)\left(\hat{\boldsymbol{x}}_{\mathrm{N}_{2} \mathrm{O}}-\boldsymbol{x}_{\mathrm{N}_{2} \mathrm{O}}^{a}\right) \\
& +\left(\mathbf{A}_{\mathrm{cj}}-\mathbf{A}_{\mathrm{nj}}\right)\left(\hat{\boldsymbol{x}}_{j}-\boldsymbol{x}_{j}^{a}\right)+\mathbf{G}_{\mathrm{R}} \mathbf{K}_{b}\left(\boldsymbol{b}-\boldsymbol{b}^{a}\right)+\mathbf{G}_{\mathrm{R}} \boldsymbol{n},
\end{aligned}
$$

where $\mathbf{G}_{\mathrm{R}}$ is the gain matrix for $\hat{\boldsymbol{x}}_{\mathrm{CH}_{4}}$ minus the gain matrix for $\hat{\boldsymbol{x}}_{\mathrm{N}_{2} \mathrm{O}}\left(\mathbf{G}_{\mathrm{R}}=\mathbf{G}_{c}-\mathbf{G}_{n}\right), \mathbf{A}_{\mathrm{nn}}$ is the averaging kernel for $\mathrm{N}_{2} \mathrm{O}, \mathbf{A}_{\mathrm{nj}}$ is the sensitivity of the retrieved $\mathrm{N}_{2} \mathrm{O}$ to all other jointly retrieved parameters, and $\mathbf{A}_{\mathrm{nc}}$ is the sensitivity of the retrieved $\mathrm{N}_{2} \mathrm{O}$ to the retrieved $\mathrm{CH}_{4}$. Note that the crossaveraging kernels are small relative to the averaging kernels for $\mathrm{N}_{2} \mathrm{O}$ and $\mathrm{CH}_{4}\left(\mathbf{A}_{\mathrm{nc}} \ll \mathbf{A}_{\mathrm{cc}}\right.$ and $\left.\mathbf{A}_{\mathrm{cn}} \ll \mathbf{A}_{\mathrm{nn}}\right)$, and so these cross-averaging kernels can be neglected.
Comparisons of Version 5 of the TES $\mathrm{CH}_{4}$ product with HIPPO showed a remaining positive bias that was generally constant with latitude (Wecht et al., 2012), and we find that the same is true in TES Version 6 (see Sect. 5.3). Thus a second, global correction is applied to the TES retrieved $\mathrm{CH}_{4}$ :

$\hat{\boldsymbol{x}}_{\mathrm{CH}_{4}}^{\mathrm{cor}}=\hat{\boldsymbol{x}}_{\mathrm{CH}_{4}}^{\mathrm{adj}}-\mathbf{A}_{\mathrm{cc}} \boldsymbol{q}$,

where each element of $\boldsymbol{q}$ is set to 0.015 , which generally minimizes the bias in the lower-tropospheric representative value for $\mathrm{CH}_{4}$ (see Sect. 5.4).

\subsection{Spectroscopic updates}

The accuracy of the radiative transfer model $\boldsymbol{F}(\boldsymbol{x})$ in Eq. (1) depends on the accuracy of the spectroscopic line parameters and continua for the various gas-phase species used to calculate the molecular absorption coefficients. Thus improvements in these spectroscopic parameters should lead to improvements in the retrieved profiles of various species, all other things being equal. Table 1 summarizes the spectroscopic parameters evaluated in this study. In going from TES Version 5 to TES Version 6, the spectroscopic parameters for $\mathrm{H}_{2} \mathrm{O}, \mathrm{CO}_{2}$, and $\mathrm{CH}_{4}$ were substantially updated based on recent evaluations of the spectroscopic parameters used in LBLRTM with ground-based and satellite radiance data (e.g., Shephard et al., 2009; Mlawer et al., 2012; Alvarado et al., 2013).

In TES Version 5, the $\mathrm{CH}_{4}$ spectroscopic parameters were taken from HITRAN 2004 (Rothman et al., 2005). For Version 6, the $\mathrm{CH}_{4}$ parameters were taken from HITRAN 2008 (Rothman et al., 2009) with first-order line coupling parameters calculated for the $v_{4}\left(\sim 1311 \mathrm{~cm}^{-1}\right)$ and $v_{3}(\sim$ $3019 \mathrm{~cm}^{-1}$ ) bands of $\mathrm{CH}_{4}$ with the method and relaxation matrices of Tran et al. (2006), as in LBLRTM v12.1. Alvarado et al. (2013) found that these updated $\mathrm{CH}_{4}$ line coupling parameters reduced the positive bias in $\mathrm{CH}_{4}$ retrievals from IASI (Infrared Atmospheric Sounding Interferometer), but that significant spectral residuals remained, most likely due to remaining errors in the $\mathrm{CH}_{4}$ spectroscopy. Furthermore, they found that including the line coupling parameters for $\mathrm{CH}_{4}$ had little impact on the retrieved $\mathrm{CH}_{4}$ profile or the mean spectroscopic residuals in the spectral range used by the retrieval $\left(1292-1305 \mathrm{~cm}^{-1}\right)$, although there was some improvement in the residuals in the $v_{4}$ Q-branch between 1305 and $1310 \mathrm{~cm}^{-1}$.

In TES Version 5, the spectroscopic parameters for $\mathrm{H}_{2} \mathrm{O}$ came from HITRAN 2004 (Rothman et al., 2005), including the 2006 updates. For Version 6, the $\mathrm{H}_{2} \mathrm{O}$ parameters were updated to HITRAN 2008, with the exception that the line positions and intensities in the range $10-2500 \mathrm{~cm}^{-1}$ were taken from Coudert et al. (2008), as in LBLRTM v12.1. Shephard et al. (2009) and Alvarado et al. (2013) showed that this combination of parameters is more consistent across the $\mathrm{H}_{2} \mathrm{O} v_{2}$ band than the HITRAN 2008 parameters alone, and that the Coudert et al. (2008) parameters lead to a $\sim 10 \%$ 
Table 1. Sources of spectroscopic line parameters used in this study.

\begin{tabular}{|c|c|c|c|}
\hline Species & TES Version 5 & TES Version 6 & Experimental version \\
\hline $\mathrm{CH}_{4}$ & HITRAN 2004 & $\begin{array}{l}\text { HITRAN } 2008^{b} \\
\text { with line mixing }\end{array}$ & $\begin{array}{l}\text { HITRAN } 2008^{\mathrm{b}} \\
\text { with line mixing }\end{array}$ \\
\hline $\mathrm{H}_{2} \mathrm{O}$ & $\begin{array}{l}\text { HITRAN } 2004^{\mathrm{a}} \\
\text { with } 2006 \text { updates }\end{array}$ & $\begin{array}{l}\text { HITRAN 2008 } \\
+ \text { Coudert et al. (2008) }\end{array}$ & $\begin{array}{l}\text { HITRAN 2008 } \\
+ \text { Coudert et al. (2008) }\end{array}$ \\
\hline $\mathrm{CO}_{2}$ & Niro et al. $(2005)^{d}$ & Lamouroux et al. (2010) ${ }^{\mathrm{d}}$ & Lamouroux et al. $(2010)^{\mathrm{d}}$ \\
\hline $\mathrm{N}_{2} \mathrm{O}$ & HITRAN $2000^{\mathrm{e}}$ & HITRAN $2000^{\mathrm{e}}$ & HITRAN $2008^{b}$ \\
\hline
\end{tabular}

reduction in the upper tropospheric $\mathrm{H}_{2} \mathrm{O}$ mixing ratio retrieved from IASI. Both versions used v2.4 of the MT_CKD self and foreign water vapor continua (Mlawer et al., 2012), as this version performs better than MT_CKD v2.5 in the CO fundamental band (Alvarado et al., 2013).

For $\mathrm{CO}_{2}$, the differences between the two sets of line parameters used in TES Version 5 and Version 6 are negligible in the regions used for $\mathrm{CH}_{4}$ retrieval. However, since the $\mathrm{CO}_{2}$ line parameters can affect the temperature retrieval, and the $\mathrm{CH}_{4}$ retrieval step uses the retrieved temperature, we include this information for completeness. For $\mathrm{CO}_{2}$, TES Version 5 used the line parameters of Niro et al. (2005), including firstorder line coupling parameters for the $\mathrm{P}, \mathrm{Q}$, and $\mathrm{R}$ branches of the $\mathrm{CO}_{2}$ bands. In TES Version 6, these are updated to the parameters of Lamouroux et al. (2010), which are based on the HITRAN 2008 line parameters and also include P-,Q-, and R-branch line coupling parameters. Both versions used the $\mathrm{CO}_{2}$ foreign continuum from MT_CKD v2.5 (Mlawer et al., 2012). Validations tests against radiosonde data showed little difference in the mean temperature profiles retrieved using the two sets of $\mathrm{CO}_{2}$ and $\mathrm{H}_{2} \mathrm{O}$ spectroscopy (B. Herman, personal communication, 16 October 2013).

In addition to the updates to $\mathrm{CH}_{4}, \mathrm{H}_{2} \mathrm{O}$, and $\mathrm{CO}_{2}$ made in TES Version 6, we also evaluate the impact of updates to the spectroscopic parameters of $\mathrm{N}_{2} \mathrm{O}$ that may be included in future TES versions. In both TES Version 5 and 6, the $\mathrm{N}_{2} \mathrm{O}$ line parameters are based on HITRAN 2000 (Rothman et al., 2003). Here we test the impact of updating these to the HITRAN 2008 parameters (Rothman et al., 2009), which include the almost complete revision of the $\mathrm{N}_{2} \mathrm{O}$ line list performed for HITRAN 2004 (Rothman et al., 2005).

\subsection{A priori profile updates}

In the optimal estimation approach, the retrieved profile of $\mathrm{CH}_{4}$ depends on the a priori estimate of the profiles of $\mathrm{CH}_{4}$, of the co-retrieved trace gases (through $\boldsymbol{x}_{\mathrm{N}_{2} \mathrm{O}}^{a}$ and $\boldsymbol{x}_{j}^{a}$ in Eq. 6) and of the a priori estimates of the profiles of temperature and other trace gases (through $\boldsymbol{b}^{a}$ in Eq. 6). The a priori estimates of temperature, $\mathrm{H}_{2} \mathrm{O}, \mathrm{N}_{2} \mathrm{O}, \mathrm{CH}_{4}$, and $\mathrm{O}_{3}$ were changed be- tween Version 5 and Version 6 of the TES products. These updates are described below.

The TES a priori profiles of temperature and $\mathrm{H}_{2} \mathrm{O}$, as well as the estimates of surface temperature and pressure, come from the NASA Global Modeling and Assimilation Office (GMAO) Goddard Earth Observing System Model, Version 5 (GEOS-5, Rienecker et al., 2008). TES Version 5 products used data from version v5.2 of the GEOS-5 model as a priori values, while TES Version 6 uses v5.9.1.

The TES Version $5 \mathrm{~N}_{2} \mathrm{O}$ a priori profiles used a monthly mean climatology every $30^{\circ}$ latitude and $60^{\circ}$ longitude based on the Model for OZone and Related chemical Tracers (MOZART)-2 chemistry-transport model (CTM) (Brasseur et al., 1998; Park et al., 2004). A yearly increase of $0.22 \%$ was applied based on the trends in surface flask measurements from the NOAA Earth System Research Laboratory (ESRL) Global Monitoring Division (GMD). TES Version 6 uses an updated monthly mean $\mathrm{N}_{2} \mathrm{O}$ climatology from the Specified Dynamics version of WACCM-4 (Marsh et al., 2013), in which the horizontal winds and temperatures are relaxed to the GEOS-5 meteorological fields in the troposphere and stratosphere. The horizontal resolution with latitude was increased from 30 to $1^{\circ}$. The simulation was done for 2004 through 2010 by Doug Kinneson (UCAR); the a priori profiles for years after 2010 were based on the 2010 data.

The $\mathrm{CH}_{4}$ climatology used for the TES Version 5 a priori consisted of monthly average fields in $10^{\circ}$ latitude bins from the same MOZART run as was used for $\mathrm{N}_{2} \mathrm{O}$ above. This previous climatology accounted for seasonal cycles, but the $\mathrm{CH}_{4}$ values for a given month were static from one year to the next. Measurements from the NOAA Global Cooperative Air Sampling Network have shown that from 1999 to 2006, globally averaged $\mathrm{CH}_{4}$ was relatively constant. However, 2007 marked a return to a positive $\mathrm{CH}_{4}$ growth rate (Dlugokencky et al., 2011). The TES Version $6 \mathrm{CH}_{4}$ climatology was updated in order to account for the post-2007 $\mathrm{CH}_{4}$ growth rate using surface flask measurements from the NOAA ESRL GMD. At the time when the work on the TES $\mathrm{CH}_{4}$ climatology update was underway, monthly mean data were available up to the end of 2010. The flask data was 
binned into $10^{\circ}$ latitude bands and an average, globally uniform increase for each year since 2004, relative to 2004, was calculated. For the years 2011 to 2014, the growth rate was extrapolated from the approximately linear growth rate observed from 2008 to 2010 inclusive.

There were also updates to the $\mathrm{O}_{3}$ climatology for TES Version 6. The impact of the $\mathrm{O}_{3}$ climatology update on the $\mathrm{CH}_{4}$ retrievals is not expected to be significant, but could have some impact via the temperature retrievals, since there are $\mathrm{O}_{3}$ lines in the $\mathrm{CO}_{2}$ region used for the temperature retrievals. For TES Version 5, the $\mathrm{O}_{3}$ a priori climatology was based on MOZART-3, which extended the earlier MOZART-2 tropospheric chemistry model into the stratosphere and mesosphere (surface $-0.001 \mathrm{hPa}$ ). The climatology had unrealistically strong vertical gradients in ozone, and thus higher-than-observed ozone abundances, in the extratropical upper troposphere lower stratosphere (UTLS) region. The ozone climatology for the TES Version $6 \mathrm{O}_{3}$ a priori was generated by merging the climatological monthly mean tropospheric/lower stratospheric ozone field from a 19972004 simulation from the MOZART-4 CTM (Emmons et al., 2010), which extends from the surface to $0.2 \mathrm{hPa}$, with the climatological monthly mean stratospheric and mesospheric ozone field from a 2005-2010 simulation from the Specified Dynamics version of WACCM. This revised $\mathrm{O}_{3}$ climatology agrees better with Microwave Limb Sounder (MLS) observations of the $\mathrm{O}_{3}$ climatology in the UTLS.

\section{$4 \quad \mathrm{TES} \mathrm{CH}_{4}$ validation methodology}

Our validation approach is based on that used by Wecht et al. (2012) to evaluate $\mathrm{CH}_{4}$ retrievals from TES V004 and V005 with data from the HIPPO I and II campaigns, and is described in detail below.

\subsection{Coincidence criteria}

One of the key issues in comparing satellite retrievals of trace gases with aircraft profiles is sampling: the aircraft generally does not sample the atmosphere in the exact time and place as the satellite observations. Thus to compare the TES and HIPPO $\mathrm{CH}_{4}$ profiles we must choose appropriate coincidence criteria in space and time. Wecht et al. (2012) found that collocation error between TES Version 4 and 5 and $\mathrm{HIPPO} \mathrm{CH}_{4}$ profiles was not significant on scales up to $750 \mathrm{~km}$ and $24 \mathrm{~h}$, most likely due to the fact that the HIPPO profiles are remote from major sources of $\mathrm{CH}_{4}$, and thus show little fine-scale variability. We thus adopt the same coincidence criteria (TES overpass within $750 \mathrm{~km}$ and $24 \mathrm{~h}$ of the HIPPO profile) here. We also require that the HIPPO profile have a sufficient number of valid $\mathrm{CH}_{4}$ data points to define the tropospheric profile using the following quality criteria: (a) there are at least 10 data points in the profile; (b) the minimum pressure in the profile was less than or equal to
Table 2. Number of TES (bold) and HIPPO (italic) scans matched for each combination of spectroscopy, a priori, and corrections. Values are given for scans with DOFS $\geq 1.6$ and DOFS $<1.6$.

\begin{tabular}{lll}
\hline Spectroscopy & TES Version 5 a priori & TES Version 6 a priori \\
\hline \multirow{2}{*}{ TES Version 5 } & DOFS $\geq 1.6: \mathbf{4 0 4}(197)$ & DOFS $\geq 1.6: \mathbf{4 0 2}(195)$ \\
& DOFS $<1.6: \mathbf{1 1 4}(56)$ & DOFS $<1.6: \mathbf{1 0 7}(50)$ \\
\hline \multirow{2}{*}{ TES Version 6 } & DOFS $\geq 1.6: \mathbf{4 0 6}(197)$ & DOFS $\geq 1.6: \mathbf{3 8 9}(191)$ \\
& DOFS $<1.6: \mathbf{1 1 1}(55)$ & DOFS $<1.6: \mathbf{1 0 8}(51)$ \\
\hline $\begin{array}{l}\text { Experimental } \\
\text { version }\end{array}$ & DOFS $\geq 1.6: \mathbf{4 0 8}(198)$ & DOFS $\geq 1.6: \mathbf{4 0 2}(195)$ \\
\hline
\end{tabular}

$250 \mathrm{hPa}$; and (c) the difference between the minimum and maximum pressure in the profile was at least $400 \mathrm{hPa}$. With these criteria, a worst-case HIPPO $\mathrm{CH}_{4}$ profile would have at least 10 valid data points between 250 and $650 \mathrm{hPa}$, which is generally adequate to define the tropospheric profile. The number of TES and HIPPO profiles matched using these criteria for each combination of spectroscopic parameters and a priori profiles is given in Table 2 .

\subsection{TES observation operator for HIPPO profiles}

A second issue with comparing satellite and aircraft profiles is that (a) the vertical resolution of the satellite profile is substantially coarser than that of the aircraft data and (b) the retrieved satellite profile reflects the influence of the choice of a priori profile (Rodgers and Connor, 2003). To address this, we first interpolate each HIPPO profile (expressed as the natural logarithm of the mixing ratio) to the 67 levels of the TES pressure grid, extrapolating above the GV ceiling using the shape of the TES a priori profile (i.e., scaling the TES a priori to match the top of the HIPPO profile) and extrapolating below the lowest altitude measured by assuming that the profile is constant below this height. We then apply the TES observation operator to the resulting HIPPO profile, $\boldsymbol{h}_{\mathrm{CH}_{4}}$

$\hat{\boldsymbol{h}}_{\mathrm{CH}_{4}}=\boldsymbol{x}_{\mathrm{CH}_{4}}^{a}+\mathbf{A}_{\mathrm{cc}}\left(\boldsymbol{h}_{\mathrm{CH}_{4}}-\boldsymbol{x}_{\mathrm{CH}_{4}}^{a}\right)$.

Here $\hat{\boldsymbol{h}}_{\mathrm{CH}_{4}}$ is the HIPPO profile corrected for the smoothing error of the TES retrieval and including the influence of the a priori $\mathrm{CH}_{4}$ profile. It represents the profile that would have been retrieved if (a) TES had sampled the same air as HIPPO and (b) the retrieval errors due to jointly retrieved parameters, other model parameters, and instrument noise were negligible.

The trace of the averaging kernel $\mathbf{A}_{\mathrm{cc}}$ gives the degrees of freedom for signal (DOFS) for the retrieval (Rodgers, 2000). The TES Version 5 and $6 \mathrm{CH}_{4}$ retrievals generally have between 0.6 and 2.3 degrees of freedom for signal (Worden et al., 2012), and thus provide at most one or two independent pieces of information on the vertical profile of 

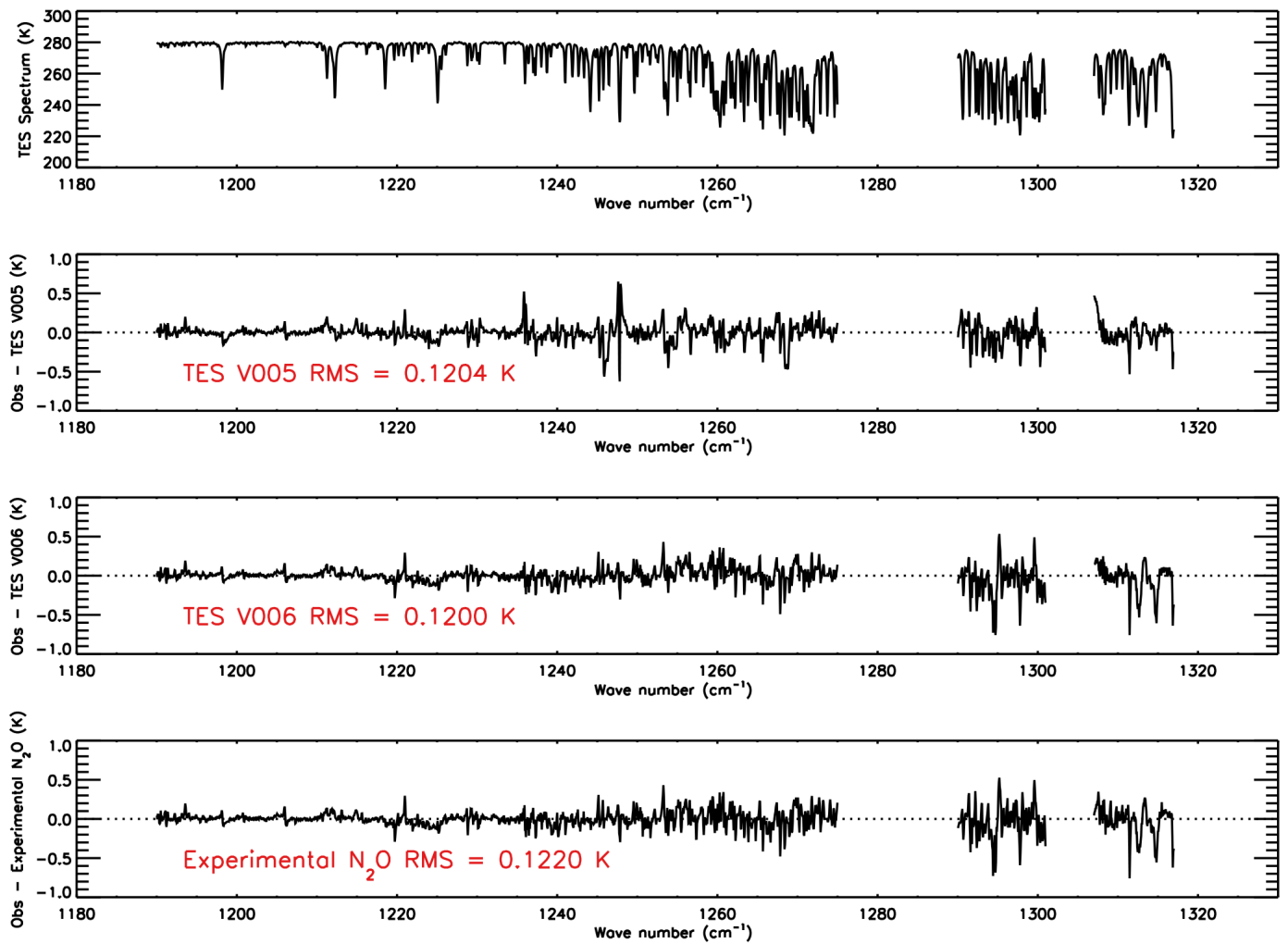

Figure 2. Mean spectral residuals after retrieval in the areas used to simultaneously retrieve $\mathrm{CH}_{4}, \mathrm{~N}_{2} \mathrm{O}, \mathrm{HDO}$, and $\mathrm{H}_{2} \mathrm{O}$ from TES radiances. (a) Example TES spectrum. (b) Mean TES residuals after TES Version 5 retrievals for the 518 TES scans analyzed in this study (see Table 2). (c) Mean TES residuals after TES Version 6 retrievals. (d) Mean TES residuals after retrievals as in TES Version 6, but with the proposed updated $\mathrm{N}_{2} \mathrm{O}$ spectroscopy from HITRAN 2008.

$\mathrm{CH}_{4}$. We thus reduce the retrieved TES $\mathrm{CH}_{4}$ profiles $\hat{\boldsymbol{x}}_{\mathrm{CH}_{4}}^{\mathrm{cor}}$ and the smoothed HIPPO profiles $\hat{\boldsymbol{h}}_{\mathrm{CH}_{4}}$ to one or two representative tropospheric volume mixing ratios (RTVMRs), following the approach of Payne et al. (2009) and Wecht et al. (2012). For TES profiles with DOFS of 1.6 or less, a single RTVMR value $\left(y_{\mathrm{R}}\right)$ was calculated by remapping the 67 level retrieved $\mathrm{CH}_{4}$ profile to a four-level grid with points at (1) the Earth's surface, (2) the altitude of maximum TES sensitivity to $\mathrm{CH}_{4}$ (i.e., the level where the sum of the rows of $\mathbf{A}_{\mathrm{cc}}$ is largest), (3) the tropopause, and (4) the top of the atmosphere, as in Payne et al. (2009). The value of the $\mathrm{CH}_{4}$ mixing ratio at the second level of this four-level grid is the RTVMR. For retrievals with DOFS of 1.6 or more, two representative values are produced by remapping the retrieved $\mathrm{CH}_{4}$ profile to a five-level grid with points at (1) the Earth's surface, (2) the altitude of the lower maximum of TES sensitivity to $\mathrm{CH}_{4}$ (defined as the level where the sum of the diagonal of $\mathbf{A}_{\mathrm{cc}}$ from the surface to this level is $20 \%$ of the DOFS), (3) the altitude of the upper maximum of TES sensitivity to $\mathrm{CH}_{4}$ (i.e., the level where the sum of the diagonal of $\mathbf{A}_{\mathrm{cc}}$ from the surface is $60 \%$ of the DOFS), (4) the tropopause, and (5) the top of the atmosphere. The remapped $\mathrm{CH}_{4}$ values at points (2) and (3) are then defined as the lower tropospheric $\left(y_{\mathrm{L}}\right)$ and upper tropospheric $\left(y_{\mathrm{U}}\right)$ representative values. The same remapping is applied to the corresponding HIPPO profiles.

\section{Changes between TES Version 5 and Version 6}

\subsection{Changes in spectral residuals}

One method for evaluating changes in the spectroscopic parameters of a radiative transfer model is to examine the remaining spectral residuals (i.e., observed minus modeled radiances or brightness temperatures) after retrieval. When averaged over a large number of spectra, remaining systematic residuals indicate likely spectroscopic errors in the radiative transfer model (e.g., Shephard et al., 2009; Alvarado et al., 2013).

Figure 2 shows the average of 518 TES brightness temperature spectra in the spectral ranges TES uses to retrieve $\mathrm{CH}_{4}$ along with the mean spectral brightness temperature residuals for TES Version 5 and Version 6. The root-mean-square (RMS) errors for each set of mean residuals are printed in red on the figure. The change to V006 has mixed results: while the spectroscopic parameters used in TES Version 6 do 

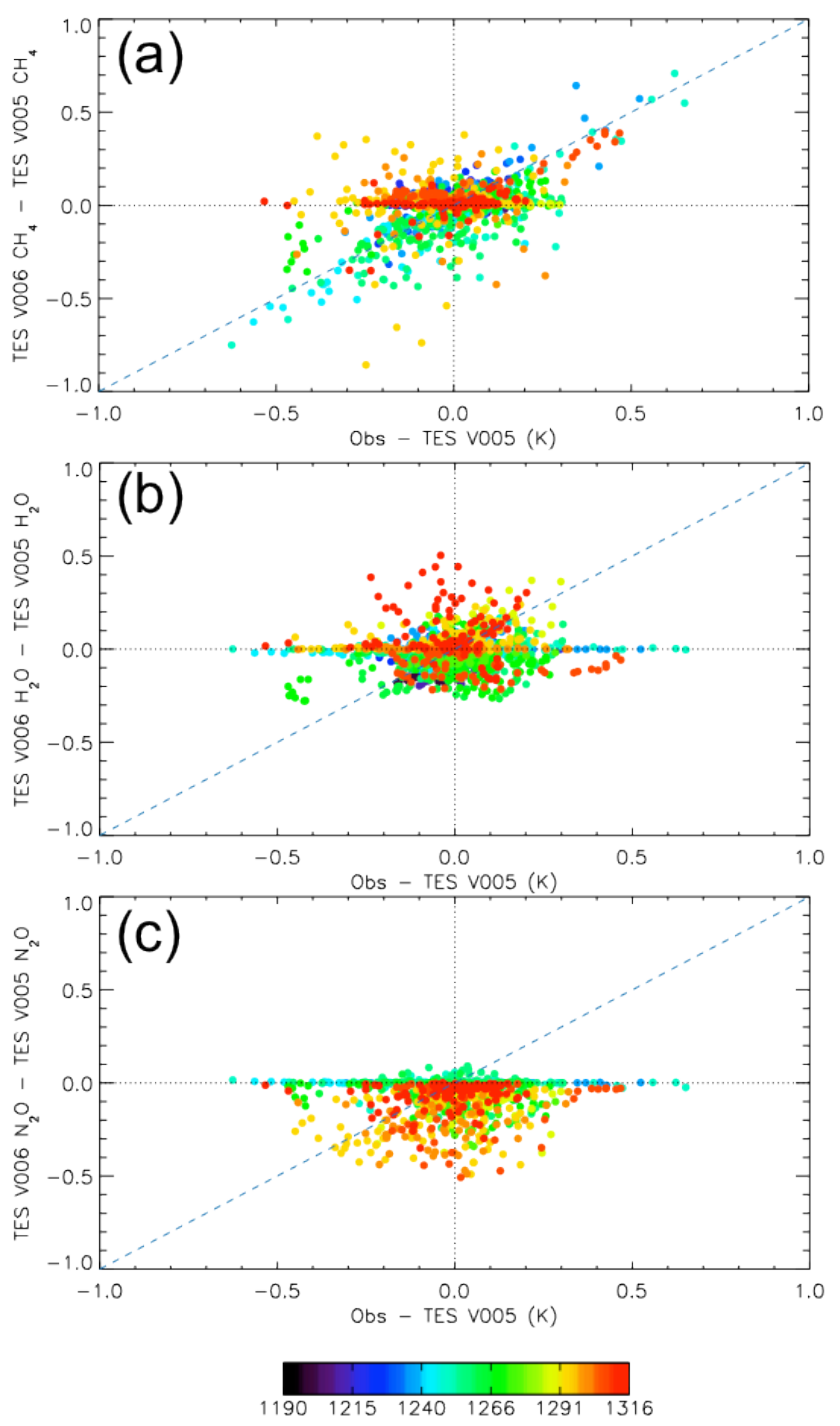

Figure 3. Plots of the TES Version 5 mean residuals for each retrieval channel versus the change in brightness temperature due to replacing the TES Version 5 spectroscopic parameters with (a) the TES Version $6 \mathrm{CH}_{4}$ parameters, (b) the TES Version $6 \mathrm{H}_{2} \mathrm{O}$ parameters, and (c) the experimental $\mathrm{N}_{2} \mathrm{O}$ parameters for the AFGL (Air Force Geophysics Laboratory) standard tropical atmosphere and a surface temperature of $300.8 \mathrm{~K}$. The points are colored according to wave number in $\mathrm{cm}^{-1}$. Points lying near the dashed blue $x=y$ line indicate an improvement in the spectroscopic parameters.

remove several of the strong residual features between 1190 and $1280 \mathrm{~cm}^{-1}$ (especially the strong residuals near $1245-$ $1247 \mathrm{~cm}^{-1}$ ), the spectral regions above $1290 \mathrm{~cm}^{-1}$ show stronger residual spikes that are generally associated with strong $\mathrm{CH}_{4}$ and $\mathrm{H}_{2} \mathrm{O}$ lines. The overall RMS decreases very slightly (by $0.0004 \mathrm{~K}$ ) in Version 6, suggesting that it is not clear if this spectroscopy is an overall improvement over that in Version 5, at least for the spectral regions used in the TES retrievals. This is also consistent with the results for the updated $\mathrm{CH}_{4}$ spectroscopic parameters in Alvarado et al. (2013), where although the introduction of line mixing improved the residuals in the Q-branch (not used in TES retrievals), the updated $\mathrm{CH}_{4}$ spectroscopy was not a clear improvement between 1292 and $1305 \mathrm{~cm}^{-1}$.

In order to separate the impact of the different spectroscopic parameter changes on the spectral residuals, Fig. 3 shows the TES Version 5 mean residuals for each retrieval channel versus the change in brightness temperature due to replacing the TES Version 5 spectroscopic parameters with (a) the TES Version $6 \mathrm{CH}_{4}$ parameters, (b) the TES Version 6 $\mathrm{H}_{2} \mathrm{O}$ parameters, and (c) the experimental $\mathrm{N}_{2} \mathrm{O}$ parameters (discussed in Sect. 6). The brightness temperature changes due to the spectroscopic parameter changes were calculated for the Air Force Geophysics Laboratory (AFGL) standard tropical profile (Anderson et al., 1986) and a surface temperature of 300.8 K using LBLRTM v12.1 (Clough et al., 2005; Alvarado et al., 2013). The points are also colored according to wave number.

In these plots, an improvement in the spectroscopy would be noted by points lying near the line $x=y$ (plotted as a dashed blue line in Fig. 3), as that would suggest that the new spectroscopy would generally move the residuals closer to 0 . This is the case for the $\mathrm{CH}_{4}$ spectroscopic updates in Fig. 3a, which show that many of the improvements in the residuals in the spectral range $1230-1270 \mathrm{~cm}^{-1}$ in Fig. 2 are primarily due to the improvements in the $\mathrm{CH}_{4}$ spectroscopic parameters in this region. In contrast, Fig. $3 \mathrm{~b}$ implies that the $\mathrm{H}_{2} \mathrm{O}$ spectroscopic updates increase the absolute value of the residuals about as often as they reduce it. These results suggest that most of the improvement in the spectroscopic residuals between TES Version 5 and TES Version 6 is due to the updated $\mathrm{CH}_{4}$ spectroscopic parameters.

\subsection{Changes in uncorrected $\mathrm{TES} \mathrm{CH}_{4}$ retrievals}

We wish to know how the updated spectroscopic parameters, along with the updated a priori profiles, impact the retrieval of $\mathrm{CH}_{4}$. We start by evaluating the errors in the "uncorrected" $\mathrm{CH}_{4}$ retrieved from TES spectra with the HIPPO data described in Sect. 2.2. In TES Version 5 these uncorrected $\mathrm{CH}_{4}$ profiles were biased high in the upper troposphere and lower stratosphere. The TES Version 5 biases for all five HIPPO campaign periods can be seen in Fig. 4, which shows the latitudinal profiles of the bias in $y_{\mathrm{L}}, y_{\mathrm{U}}$, and $y_{\mathrm{R}}$ for TES Versions 5 and 6 . The blue triangles are the TES-HIPPO differences for the individual TES scans, with blue lines showing the estimated retrieval error reported with the TES retrievals. The black circles are the mean bias for the scans binned by $10^{\circ}$ latitude, while the black error bars represent the standard deviation in each bin. The dashed black line is the mean bias for each parameter. The uncorrected $\mathrm{CH}_{4}$ retrievals from TES Version 5 show a strong positive mean bias of $123 \pm 58 \mathrm{ppbv}$ in the upper tropospheric representative value $y_{\mathrm{U}}$, over twice as large as the bias in the lower tropospheric representative value $y_{\mathrm{L}}(46.8 \pm 42.6 \mathrm{ppbv})$ and the RTVMR 
TES Version 5

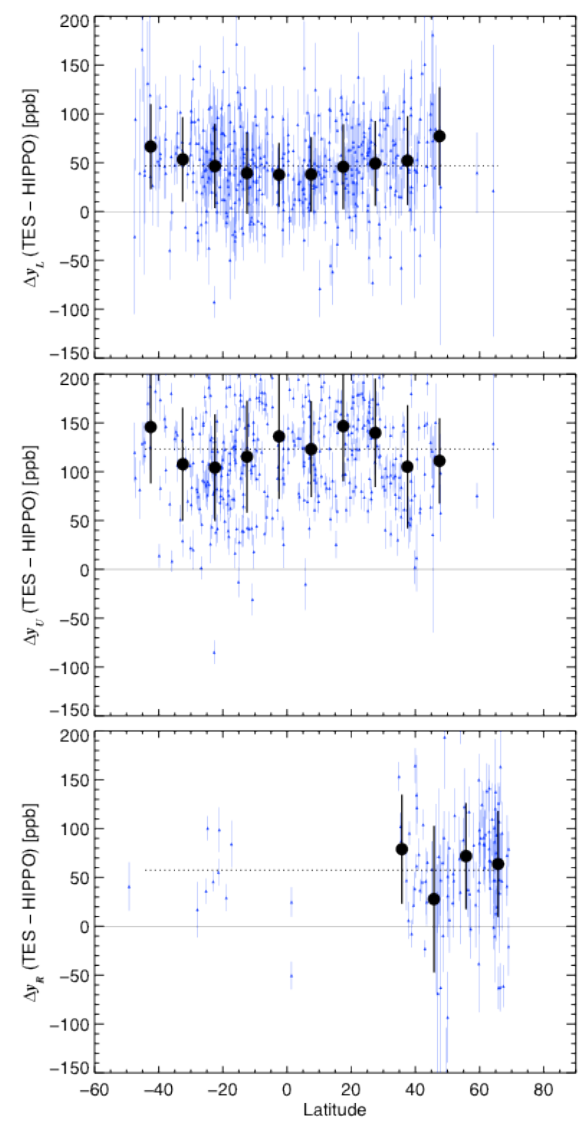

TES Version 6

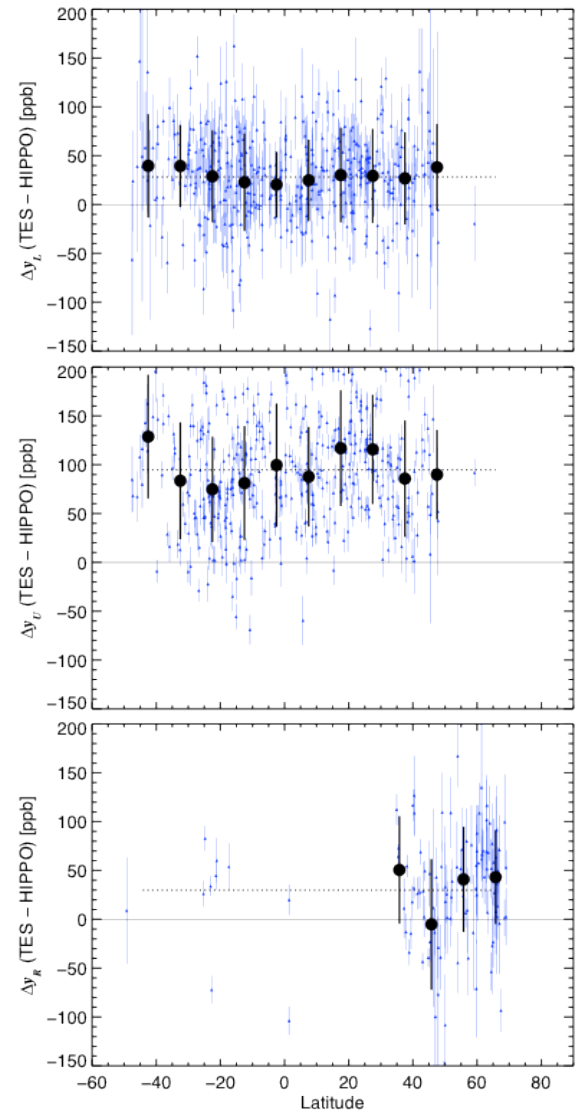

Figure 4. Latitudinal profiles of the differences between the uncorrected $\mathrm{TES} \mathrm{CH}_{4}$ retrievals and $\mathrm{HIPPO} \mathrm{CH}_{4}$ measurements for all five HIPPO campaigns. The left column has the results for TES Version 5, and the right column has the results for TES Version 6 . The top two panels of each column show the results for the upper and lower tropospheric representative volume mixing ratios $\left(\Delta y_{\mathrm{L}}\right.$ and $\Delta y_{\mathrm{U}}$, respectively) for TES retrievals where the degrees of freedom for signal (DOFS) is $\geq 1.6$. The bottom panel shows the results for the RTVMR ( $\Delta y_{\mathrm{R}}$ ) in scenes where the DOFS is $<1.6$. The blue triangles are the differences for the individual TES retrievals, with blue lines showing the estimated retrieval error. The black circles show the mean bias for the scans binned by $10^{\circ}$ latitude, while the black error bars are the standard deviation in each bin. Circles are only plotted when at least 10 scans are in a bin.

$y_{\mathrm{R}}(57.4 \pm 60.6 \mathrm{ppbv})$. However, these biases in the uncorrected TES $\mathrm{CH}_{4}$ are all substantially reduced in TES Version 6: the mean bias in $y_{\mathrm{U}}$ is decreased to $94.8 \pm 59.1 \mathrm{ppbv}$, the mean bias in $y_{\mathrm{L}}$ is reduced to $28.3 \pm 45.9 \mathrm{ppbv}$, and the mean bias in $y_{\mathrm{R}}$ is reduced to $29.8 \pm 58.8 \mathrm{ppbv}$. This is consistent with the findings of Alvarado et al. (2013), who found that these updated $\mathrm{H}_{2} \mathrm{O}$ and $\mathrm{CH}_{4}$ spectroscopic parameters reduced the positive mean bias in the average $\mathrm{CH}_{4}$ retrieved from 120 IASI spectra below the $100 \mathrm{hPa}$ surface by $44 \mathrm{ppbv}$. Therefore we conclude that the updated $\mathrm{CH}_{4}$ spectroscopic parameters in TES Version 6 substantially reduce the positive bias in the retrieved $\mathrm{CH}_{4}$ profiles prior to the application of any corrections. However, the remaining bias in the uncorrected $\mathrm{CH}_{4}$ profiles from TES Version 6 suggest that further improvement of the $\mathrm{CH}_{4}$ spectroscopic parameters is needed to remove the necessity of the $\mathrm{N}_{2} \mathrm{O}$-based correction.

\subsection{Changes in the $\mathrm{N}_{2} \mathrm{O}$-corrected $\mathrm{TES}_{\mathrm{CH}_{4}}$ retrievals}

As discussed by Worden et al. (2012) and noted in Sect. 3, much of the bias in the retrieved TES $\mathrm{CH}_{4}$ can be removed through the use of a correction that assumes (a) that any deviations of the retrieved $\mathrm{N}_{2} \mathrm{O}$ profile from its a priori value are the result of systematic error and (b) that systematic errors that affect the retrieved TES $\mathrm{N}_{2} \mathrm{O}$ profiles also impact the co-retrieved $\mathrm{CH}_{4}$. This " $\mathrm{N}_{2} \mathrm{O}$-corrected" $\mathrm{CH}_{4}$ retrieval is what is used in atmospheric studies that use TES $\mathrm{CH}_{4}$ (e.g., Worden et al., 2013a, b) and is provided in the TES "lite" product files. In this section we examine the remaining bias in the TES $\mathrm{CH}_{4}$ retrievals from Version 5 and 6 after this correction has been applied, but before the application of global bias correction given by Eq. (7). The impact of the global bias correction is discussed in Sect. 5.4 below. 
TES Version 5

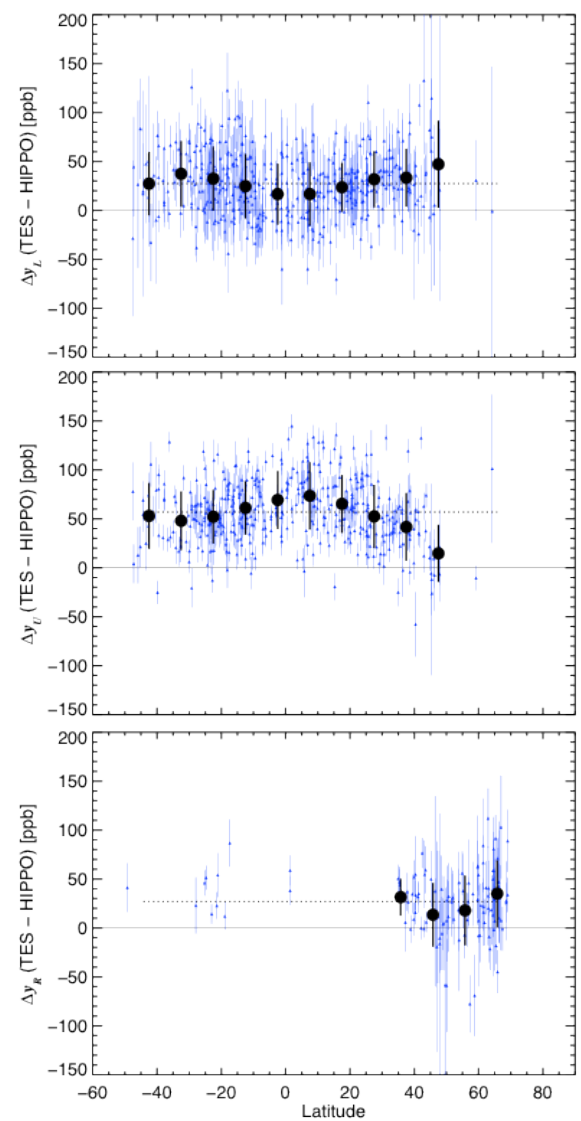

TES Version 6

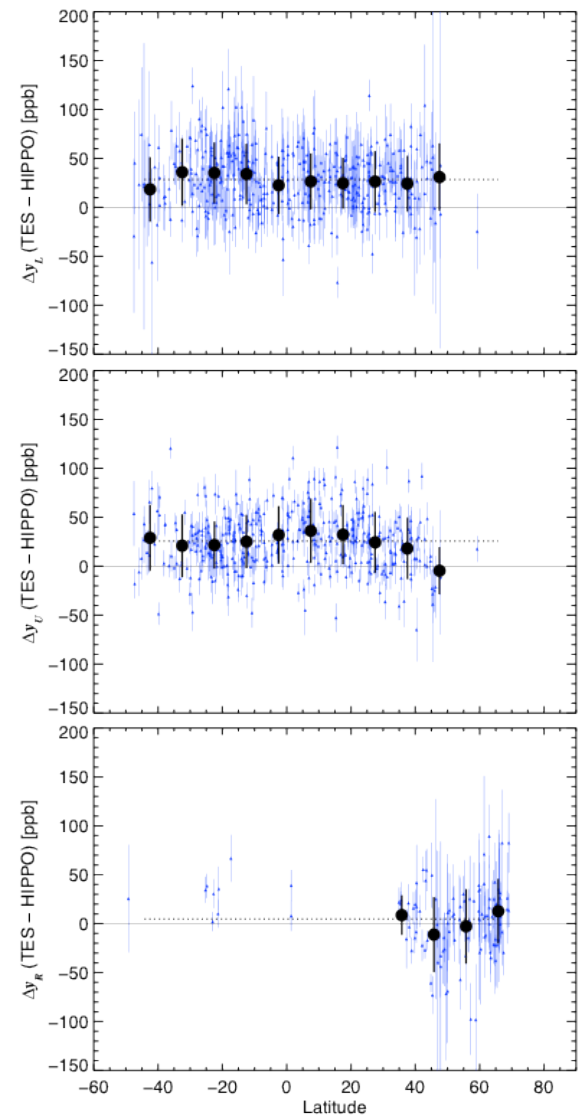

Figure 5. As in Fig. 4, but for the $\mathrm{N}_{2} \mathrm{O}$-corrected TES $\mathrm{CH}_{4}$ retrievals (see Eq. (5) and Worden et al., 2012).

Table 3. Mean bias $\left( \pm 1 \sigma\right.$, in ppb) of the lower $\left(y_{\mathrm{L}}\right)$ and upper $\left(y_{\mathrm{U}}\right)$ troposphere RTVMR for TES $\mathrm{CH}_{4}$ retrievals with DOFS $\geq 1.6$ and overall RTVMR $\left(y_{\mathrm{R}}\right)$ for retrievals with DOFS $<1.6$.

\begin{tabular}{lccccc}
\hline Spectroscopy & \multicolumn{2}{c}{ TES Version 5 a priori } & & \multicolumn{2}{c}{ TES Version 6 a priori } \\
\cline { 2 - 3 } \cline { 5 - 6 } & $\begin{array}{c}\text { With } \mathrm{N}_{2} \mathrm{O} \text { correction } \\
\text { applied }\end{array}$ & $\begin{array}{c}\text { With } \mathrm{N}_{2} \mathrm{O} \text { and bias } \\
\text { correction applied }\end{array}$ & & $\begin{array}{c}\text { With } \mathrm{N}_{2} \mathrm{O} \text { correction } \\
\text { applied }\end{array}$ & $\begin{array}{c}\text { With } \mathrm{N}_{2} \mathrm{O} \text { and bias } \\
\text { correction applied }\end{array}$ \\
\hline \multirow{3}{*}{ TES Version 5 } & $y_{\mathrm{U}}: 56.9 \pm 32.8$ & $y_{\mathrm{U}}: 28.7 \pm 32.5$ & & $y_{\mathrm{U}}: 56.2 \pm 32.4$ & $y_{\mathrm{U}}: 28.1 \pm 32.2$ \\
& $y_{\mathrm{L}}: 27.3 \pm 33.0$ & $y_{\mathrm{L}}: 2.0 \pm 31.7$ & & $y_{\mathrm{L}}: 26.9 \pm 32.0$ & $y_{\mathrm{L}}: 1.6 \pm 31.7$ \\
& $y_{\mathrm{R}}: 26.8 \pm 33.0$ & $y_{\mathrm{R}}: 2.7 \pm 32.7$ & & $y_{\mathrm{R}}: 24.6 \pm 34.7$ & $y_{\mathrm{R}}: 0.2 \pm 34.4$ \\
\hline \multirow{3}{*}{ TES Version 6 } & $y_{\mathrm{U}}: 25.6 \pm 31.0$ & $y_{\mathrm{U}}:-2.1 \pm 30.6$ & & $y_{\mathrm{U}}: 25.7 \pm 30.4$ & $y_{\mathrm{U}}:-2.0 \pm 30.0$ \\
& $y_{\mathrm{L}}: 29.1 \pm 30.0$ & $y_{\mathrm{L}}: 3.8 \pm 29.6$ & & $y_{\mathrm{L}}: 28.4 \pm 30.5$ & $y_{\mathrm{L}}: 3.0 \pm 30.0$ \\
& $y_{\mathrm{R}}: 6.1 \pm 36.8$ & $y_{\mathrm{R}}:-17.8 \pm 36.5$ & & $y_{\mathrm{R}}: 4.8 \pm 35.0$ & $y_{\mathrm{R}}:-19.4 \pm 34.7$ \\
\hline \multirow{3}{*}{ Experimental version } & $y_{\mathrm{U}}: 60.8 \pm 31.7$ & $y_{\mathrm{U}}: 32.6 \pm 31.3$ & & $y_{\mathrm{U}}: 59.8 \pm 31.3$ & $y_{\mathrm{U}}: 31.6 \pm 30.8$ \\
& $y_{\mathrm{L}}: 38.1 \pm 30.2$ & $y_{\mathrm{L}}: 12.6 \pm 29.8$ & & $y_{\mathrm{L}}: 38.3 \pm 30.9$ & $y_{\mathrm{L}}: 12.7 \pm 30.5$ \\
& $y_{\mathrm{R}}: 30.4 \pm 34.6$ & $y_{\mathrm{R}}: 6.3 \pm 34.1$ & & $y_{\mathrm{R}}: 28.5 \pm 36.3$ & $y_{\mathrm{R}}: 3.9 \pm 35.7$
\end{tabular}

Table 3 gives the mean bias and standard deviation of the errors between the TES and HIPPO profiles, as determined by the representative values $y_{\mathrm{L}}, y_{\mathrm{U}}$, and $y_{\mathrm{R}}$, for each combination of spectroscopic parameters, a priori profiles, and corrections. For $\mathrm{N}_{2} \mathrm{O}$-corrected TES $\mathrm{CH}_{4}$ retrievals with DOFS $\geq 1.6$, the positive mean bias of the lower tropospheric RTVMR $\left(y_{\mathrm{L}}\right)$ only increases slightly between Versions 5 and $6(27.3 \pm 33.0 \mathrm{ppbv}$ and $28.4 \pm 30.5 \mathrm{ppbv}$, respectively). However, the positive mean bias of the upper tropospheric RTVMR $\left(y_{\mathrm{U}}\right)$ decreases by more than half (from 


\section{TES Version 5}
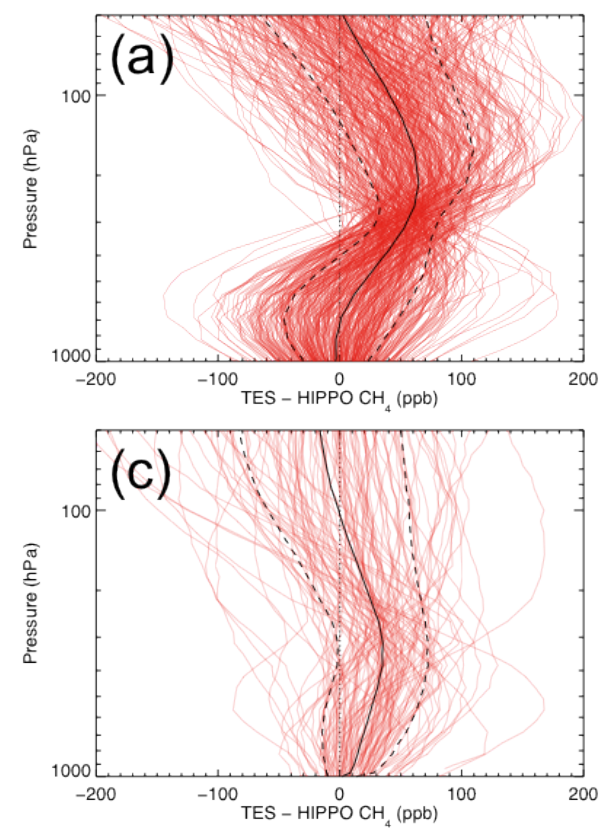

\section{TES Version 6}
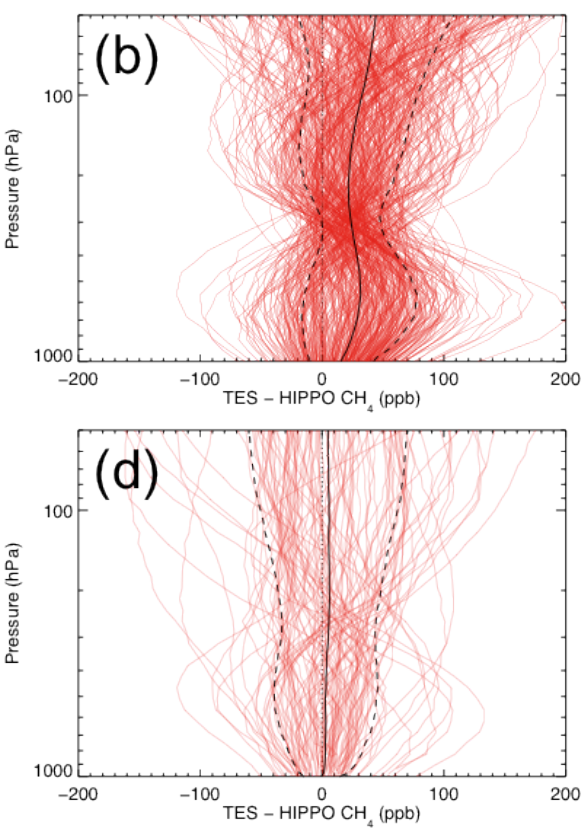

Figure 6. The differences between the $\mathrm{N}_{2} \mathrm{O}$-corrected $\mathrm{TES} \mathrm{CH}_{4}$ retrievals (see Eq. (5) and Worden et al., 2012) and the $\mathrm{HIPPO} \mathrm{CH}_{4}$ profiles versus pressure (altitude). Red lines are the differences for individual TES retrievals. The solid black line is the mean difference and the dashed black lines show the standard deviation. Panels (a) and (c) are the TES Version $5 \mathrm{CH}_{4}$ retrievals with DOFS $\geq 1.6$ and DOFS $<1.6$, respectively. Panels (b) and (d) are the TES Version $6 \mathrm{CH}_{4}$ retrievals with DOFS $\geq 1.6$ and DOFS $<1.6$, respectively.

$56.9 \pm 32.8 \mathrm{ppbv}$ for Version 5 to $25.7 \pm 30.4 \mathrm{ppbv}$ for Version 6). For $\mathrm{N}_{2} \mathrm{O}$-corrected TES retrievals with DOFS $<1.6$, the positive mean bias of the single RTVMR value $\left(y_{\mathrm{R}}\right)$ also decreases dramatically between Versions 5 and 6 (from $26.8 \pm 33.0$ to $4.8 \pm 35.0 \mathrm{ppbv})$. The results in Table 3 show that this decrease in the bias of $y_{\mathrm{U}}$ and $y_{\mathrm{R}}$ is primarily due to the spectroscopic changes between TES Versions 5 and 6 , with the a priori changes having a minor impact (see also Sect. 5.5). The spectroscopic changes made in TES Version 6 thus significantly reduce, but do not eliminate, the positive bias in the TES $\mathrm{CH}_{4}$ profiles that remains after the $\mathrm{N}_{2} \mathrm{O}$ correction is applied.

In order to evaluate the TES $\mathrm{CH}_{4}$ retrievals, we must also look at the dependence of the retrieval bias against (a) latitude and (b) altitude. Figure 5 shows the latitudinal profiles of the bias in $y_{\mathrm{L}}, y_{\mathrm{U}}$, and $y_{\mathrm{R}}$ for TES Versions 5 and 6 (again with only the $\mathrm{N}_{2} \mathrm{O}$ correction applied). For TES retrievals with DOFS $\geq 1.6$, the average bias within a latitude bin for both $y_{\mathrm{L}}$ and $y_{\mathrm{U}}$ is fairly constant with latitude between $50^{\circ} \mathrm{S}$ and $40^{\circ} \mathrm{N}$ in TES Version 6, with the changes in the bias with latitude in this range less pronounced than in Version 5: The difference between the minimum and maximum bias of the bins is $20.7 \mathrm{ppbv}\left(y_{\mathrm{L}}\right)$ and $31.9 \mathrm{ppbv}\left(y_{\mathrm{U}}\right)$ in Version 5, but only $17.6 \mathrm{ppbv}\left(y_{\mathrm{L}}\right)$ and $17.9 \mathrm{ppbv}\left(y_{\mathrm{U}}\right)$ in Version 6. North of $40^{\circ} \mathrm{N}$, nearly all the TES retrievals have less than 1.6 DOFS, and so have a single RTVMR $\left(y_{\mathrm{R}}\right)$. The changes in the bias of $y_{\mathrm{R}}$ with latitude north of $40^{\circ} \mathrm{N}$ are similar between TES Version 5 and 6 (21.6 and 23.9 ppbv between the minimum and maximum bins, respectively), and are slightly larger than those seen for the high DOFS retrievals south of $40^{\circ} \mathrm{N}$ in Version 6.

The greater similarity between the remaining positive bias in $y_{\mathrm{L}}$ and $y_{\mathrm{U}}$ in TES Version 6 already suggests that the bias is more constant with altitude in Version 6 than in Version 5. This is confirmed by Fig. 6, which shows the differences between the TES and HIPPO profiles versus pressure for each retrieval in red, with the mean and standard deviation of these differences plotted in black. The left column has results for TES Version 5, with Version 6 results on the right, while the top row is for retrievals with DOFS $\geq 1.6$ and the bottom row is for DOFS $<1.6$. We can see that while there were large swings in the mean bias versus altitude in Version 5, the mean biases in Version 6 are fairly constant with height. However, the error for any individual scan seems to create an "S" shape or an "inverted S" shape, with a cross point at $\sim 300 \mathrm{hPa}$. While these vertically varying errors cancel out in the average for TES Version 6, further work is still needed to explain the origin of these " $\mathrm{S}$ " and "inverted $\mathrm{S}$ " error patterns with height, and to find a method to remove them from the retrieval results or mitigate their impacts.

Figure 7 shows the vertical structure of the theoretical observation errors for each TES $\mathrm{CH}_{4}$ retrieval for both 
TES Version 5
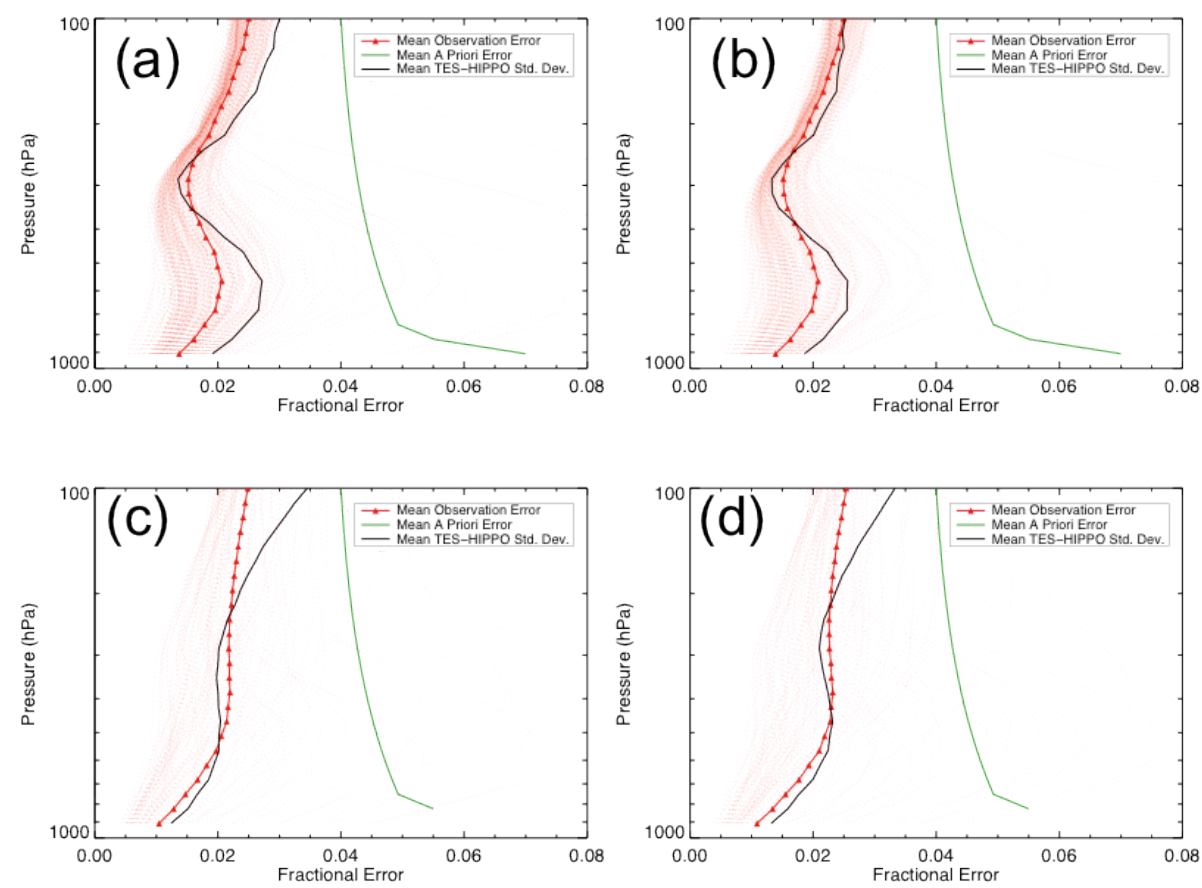

TES Version 6

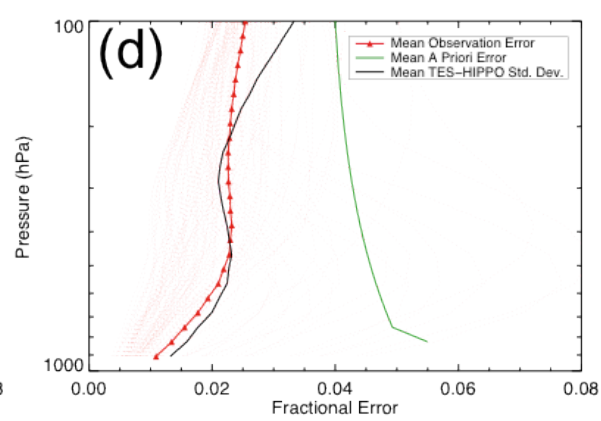

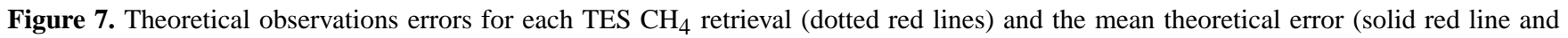
triangles) versus pressure, along with the mean a priori error estimate (green line) and the standard deviation of the TES-HIPPO differences. (a) and (c) are the TES Version $5 \mathrm{CH}_{4}$ retrievals with DOFS $\geq 1.6$ and DOFS $<1.6$, respectively. (b) and (d) are the TES Version $6 \mathrm{CH}_{4}$ retrievals with DOFS $\geq 1.6$ and DOFS $<1.6$, respectively.

Versions 5 and 6 and for the mean of the retrievals, along with the actual errors, where the latter is defined as the standard deviation of the TES-HIPPO $\mathrm{CH}_{4}$ differences after the $\mathrm{N}_{2} \mathrm{O}$-based correction $\left(\hat{\boldsymbol{x}}_{\mathrm{CH}_{4}}^{\text {adj }}-\hat{\boldsymbol{h}}_{\mathrm{CH}_{4}}\right)$. For $\mathrm{CH}_{4}$ retrievals with DOFS $\geq 1.6$, the mean actual errors in TES Version 6 are smaller and closer to the mean theoretical errors than in TES Version 5 above $300 \mathrm{hPa}$ and are also slightly improved in the lower error peak near $560 \mathrm{hPa}(0.0255$ in Version 6 versus 0.0272 in Version 5). The errors for retrievals with less than 1.6 DOFS are fairly similar between the two versions.

\subsection{Impact of the global bias correction}

As discussed above, a global bias correction following Eq. (7), with every element of the vector $\boldsymbol{q}$ set to 0.015 was found to generally remove the remaining bias in the lower tropospheric representative value $\left(y_{\mathrm{L}}\right)$ from TES Version 5. This can be seen in Table 3, which shows that for Version 5 TES $\mathrm{CH}_{4}$ retrievals with DOFS $\geq 1.6$ the positive mean bias $y_{\mathrm{L}}$ is reduced from $27.3 \pm 33.0$ to $2.0 \pm 31.7 \mathrm{ppbv}$ by the global bias correction. In addition, the bias in $y_{\mathrm{U}}$ in Version 5 is reduced from $56.9 \pm 32.8$ to $28.7 \pm 32.5$ ppbv by the global bias correction, and the positive mean bias $y_{\mathrm{R}}$ is reduced from $26.8 \pm 33.0$ to $2.7 \pm 32.7 \mathrm{ppbv}$.
Table 3 also shows that this same global bias correction nearly eliminates the bias in $y_{\mathrm{L}}$ and $y_{\mathrm{U}}$ in Version 6, decreasing from $28.4 \pm 30.5$ to $3.0 \pm 30.0$ and from $25.7 \pm 30.4$ to $-2.0 \pm 30.0$, respectively. Figures 8 and 9 show that the relative latitudinal and vertical dependence of the errors in $y_{\mathrm{L}}$ and $y_{\mathrm{U}}$ are mostly unchanged by this bias correction as well. However, the global bias correction results in a negative bias of $-19.4 \pm 34.7 \mathrm{ppbv}$ for the TES Version 6 retrievals with DOFS $<1.6$ (primarily north of $40^{\circ} \mathrm{N}$ ).

In addition to the RTVMR approach of Payne et al. (2009), another common way of using TES $\mathrm{CH}_{4}$ data is to calculate a tropospheric average VMR by averaging the TES retrieved VMR between $900 \mathrm{hPa}$ and the tropopause, as was done in Worden et al. (2013a, b). Figure 10 shows the difference of the TES and HIPPO average tropospheric VMR versus latitude after the $\mathrm{N}_{2} \mathrm{O}$ and global bias corrections have been applied. These results are very similar to the corresponding RTVMR results in Fig. 8, with the TES Version 6 spectroscopy reducing the positive bias in the average tropospheric VMR from $15.7 \pm 17.1$ to $2.1 \pm 17.1 \mathrm{ppbv}$ for retrievals with DOFS $\geq 1.6$, while changing a positive bias of $6.6 \pm 32.0 \mathrm{ppbv}$ to a negative bias of $-18.2 \pm 33.9 \mathrm{ppbv}$ in retrievals with DOFS $<1.6$. 
TES Version 5
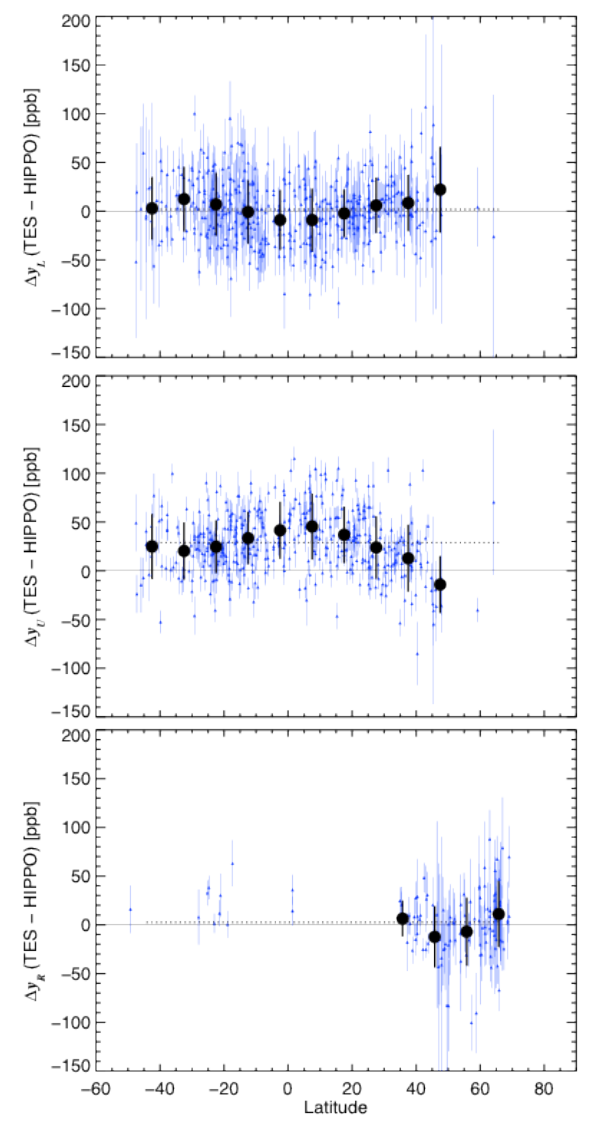

TES Version 6

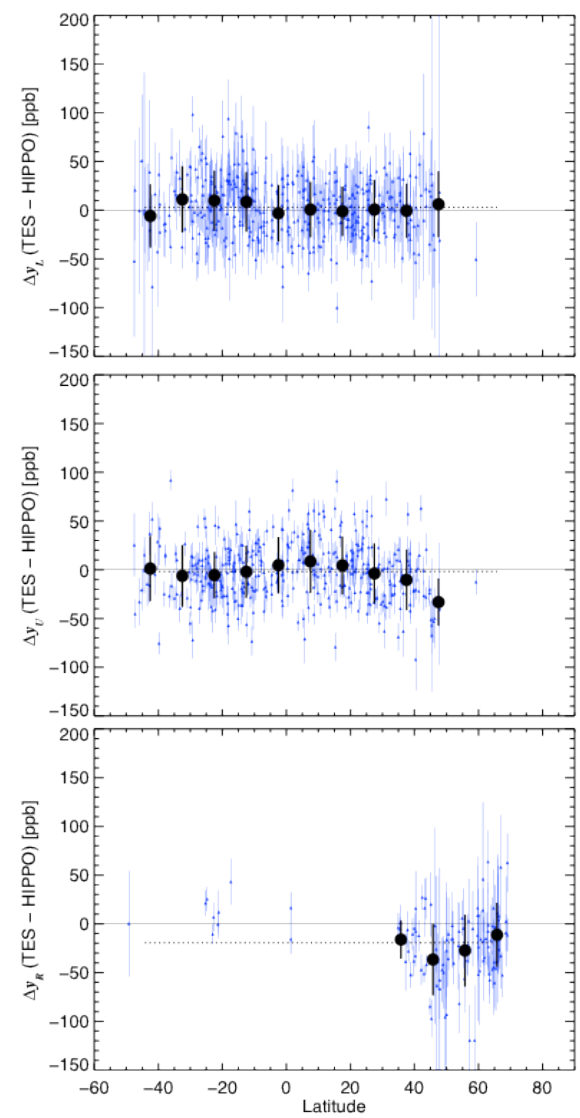

Figure 8. As in Fig. 5, but with the global bias correction (Eq. (7) and Sect. 5.4) applied.

\subsection{Impact of the a priori changes}

The changes to the a priori estimates of temperature, $\mathrm{H}_{2} \mathrm{O}$, $\mathrm{N}_{2} \mathrm{O}, \mathrm{CH}_{4}, \mathrm{O}_{3}$, and $\mathrm{CO}_{2}$ between TES Version 5 and Version 6 have a minor impact on the $\mathrm{CH}_{4}$ retrievals, as can be seen in Table 3. Using the TES Version 6 spectroscopic parameters, the mean bias in the lower tropospheric RTVMR ( $y_{\mathrm{L}}$, after both the $\mathrm{N}_{2} \mathrm{O}$ correction and the global bias correction) improves slightly from $3.8 \pm 29.6$ to $3.0 \pm 30.0 \mathrm{ppbv}$, as does the upper tropospheric value $y_{\mathrm{U}}$ (from $-2.1 \pm 30.6$ to $-2.0 \pm 30.0 \mathrm{ppbv}$ ), while the mean bias in $y_{\mathrm{R}}$ for scans with less than 1.6 DOFS becomes slightly worse (from $-17.8 \pm$ 36.5 to $-19.4 \pm 35.7 \mathrm{ppbv}$ ). The a priori profiles also have a negligible impact on the dependence of the $\mathrm{CH}_{4}$ bias with latitude and the vertical profile of the bias (not shown). Thus the reduction in positive bias seen between Version 5 and Version 6 is primarily due to the improvements in the spectroscopic parameters for $\mathrm{CH}_{4}$ and other species discussed in Sect. 3.1.

\section{Impact of proposed updates to $\mathrm{N}_{2} \mathrm{O}$ spectroscopic parameters}

\subsection{Impact on the spectral residuals}

Figure 2d shows the mean spectral residuals after the $\mathrm{CH}_{4}$ retrieval when the TES Version 6 spectroscopy is modified to include the updated $\mathrm{N}_{2} \mathrm{O}$ spectroscopic parameters from HITRAN 2008 (the "experimental version" in Table 1). The main difference from the mean residuals from TES Version 6 is an increase in the number of residual spikes between 1260 $1275 \mathrm{~cm}^{-1}$, resulting in a "fuzzier" appearance of the residuals in this region. The overall RMS error is also slightly increased from Version 6 (by $0.002 \mathrm{~K}$ ). In addition, Fig. 3c suggests that the updated $\mathrm{N}_{2} \mathrm{O}$ spectroscopic parameters worsen the spectral residuals about as often as they improve them, consistent with the increase in the overall RMS. Thus the analysis of the residuals after retrieval does not suggest that the updated $\mathrm{N}_{2} \mathrm{O}$ spectroscopic parameters are a significant improvement over the parameters used in TES Version 6, but neither do they introduce significantly larger errors. 


\section{TES Version 5}
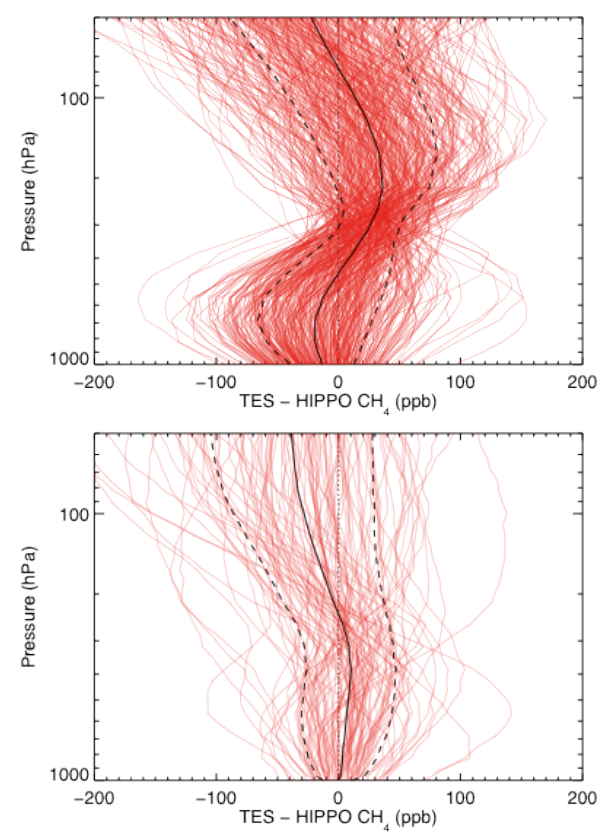

\section{TES Version 6}
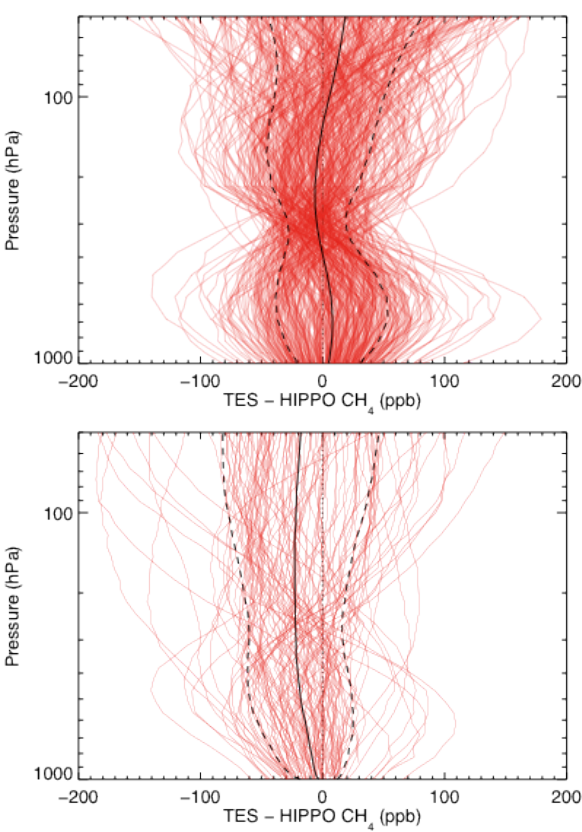

Figure 9. As in Fig. 6, but with the global bias correction (Eq. (7) and Sect. 5.4) applied.

\subsection{Impact on $\mathrm{TES}^{-2} \mathrm{CH}_{4}$ retrievals}

The results in Table 3 show that the use of the updated $\mathrm{N}_{2} \mathrm{O}$ spectroscopy generally increases the bias in the $\mathrm{CH}_{4}$ retrievals over Version 6 . When the Version 6 a priori profiles are used and only the $\mathrm{N}_{2} \mathrm{O}$ correction is applied, the bias in $y_{\mathrm{U}}$ and $y_{\mathrm{L}}$ increases from $25.7 \pm 30.4$ and $28.4 \pm 30.5 \mathrm{ppbv}$, respectively, in Version 6 to $59.8 \pm 31.3$ and $38.3 \pm 30.9 \mathrm{ppbv}$, respectively. In addition, the bias in $y_{\mathrm{R}}$ also increases from $4.8 \pm 35.0$ to $28.5 \pm 36.3 \mathrm{ppbv}$.

The impact of the $\mathrm{N}_{2} \mathrm{O}$ spectroscopic parameters on the $\mathrm{N}_{2} \mathrm{O}$-corrected TES $\mathrm{CH}_{4}$ retrievals does not arise through changes in the uncorrected $\mathrm{CH}_{4}$ profile retrieved, but rather is due to a reduction in strength in the $\mathrm{N}_{2} \mathrm{O}$ correction. Figure 11 compares the uncorrected $\mathrm{CH}_{4}$ profiles retrieved in TES Version 6 with those retrieved by the experimental version. We can see that the mean bias in the uncorrected $\mathrm{CH}_{4}$ profiles is nearly identical in these cases. However, Fig. 12 shows the $\mathrm{N}_{2} \mathrm{O}$ profiles retrieved by both versions of the TES algorithm with the $\mathrm{N}_{2} \mathrm{O}$ observations from HIPPO. We can see that the updated $\mathrm{N}_{2} \mathrm{O}$ spectroscopic parameters in the experimental version have reduced the bias in the TES retrieved $\mathrm{N}_{2} \mathrm{O}$, which would suggest that the updated $\mathrm{N}_{2} \mathrm{O}$ spectroscopy is an improvement. Reducing the bias of the retrieved $\mathrm{N}_{2} \mathrm{O}$ reduces the strength of the $\mathrm{N}_{2} \mathrm{O}$ correction via Eq. (5), and thus less of the bias in the $\mathrm{CH}_{4}$ profiles is removed than is the case in TES Version 6. Thus the $\mathrm{N}_{2} \mathrm{O}$ correction method of Worden et al. (2012), which works reasonably well to remove the bias in the retrieved $\mathrm{CH}_{4}$ for TES
Versions 5 and 6 (using HITRAN $2000 \mathrm{~N}_{2} \mathrm{O}$ parameters), is less effective with the updated $\mathrm{N}_{2} \mathrm{O}$ spectroscopic parameters from HITRAN 2008. However, we note that even with the updated $\mathrm{N}_{2} \mathrm{O}$ spectroscopic parameters it is better to use the $\mathrm{N}_{2} \mathrm{O}$-corrected TES $\mathrm{CH}_{4}$ data for scientific studies than the raw $\mathrm{CH}_{4}$ retrievals.

In order to determine why the $\mathrm{N}_{2} \mathrm{O}$-based correction method is less effective with the experimental version of the TES $\mathrm{CH}_{4}$, we examined the assumptions behind the correction method. As stated in Sect. 5.3 above, the $\mathrm{N}_{2} \mathrm{O}$-based correction method assumes that any deviations from the TES $\mathrm{N}_{2} \mathrm{O}$ a priori are due to systematic errors. We can examine the validity of this assumption by comparing the TES $\mathrm{N}_{2} \mathrm{O}$ a priori profiles from TES Version 5 and 6 with the measured $\mathrm{N}_{2} \mathrm{O}$ profiles from HIPPO, as shown in Fig. 13. We can see that for cases where the TES $\mathrm{CH}_{4}$ retrievals have at least 1.6 DOFS, which are generally in latitudes between $50^{\circ} \mathrm{S}$ and $50^{\circ} \mathrm{N}$, the assumption that on average the TES $\mathrm{N}_{2} \mathrm{O}$ a priori is generally the same as the true $\mathrm{N}_{2} \mathrm{O}$ profile appears to be valid - while individual $\mathrm{N}_{2} \mathrm{O}$ a priori profiles can show differences of up to $5 \mathrm{ppbv}$ from the HIPPO measurements, the mean of the differences is very small $(<0.5 \mathrm{ppbv})$. The difference between the TES $\mathrm{N}_{2} \mathrm{O}$ a priori and HIPPO is larger for cases where the TES $\mathrm{CH}_{4}$ retrievals have less than 1.6 DOFS, which are generally in latitudes north of $40^{\circ} \mathrm{N}$. Here the mean difference between the $\mathrm{N}_{2} \mathrm{O}$ a priori and the HIPPO observations is $\sim 1.5 \mathrm{ppbv}$, with the TES a priori generally underestimating the HIPPO $\mathrm{N}_{2} \mathrm{O}$ profile. However, in both cases the differences are fairly minor, especially compared 
TES Version 5
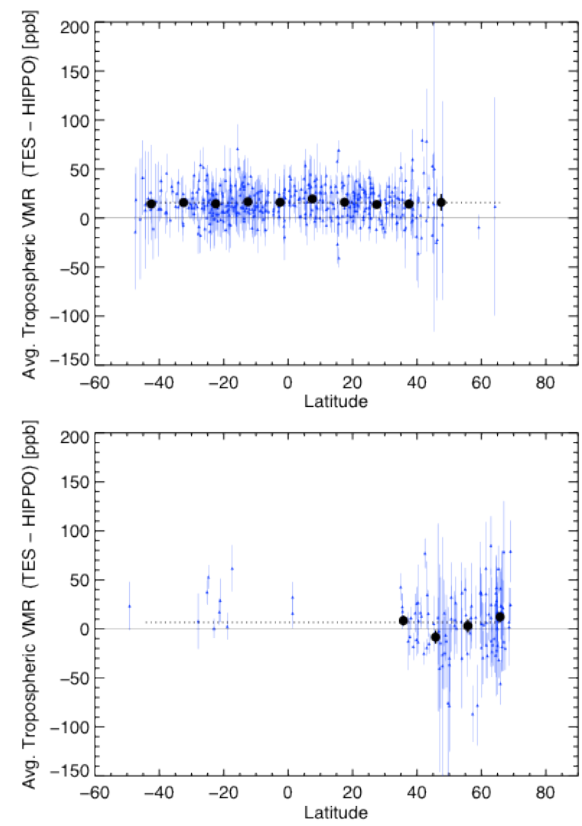

TES Version 6
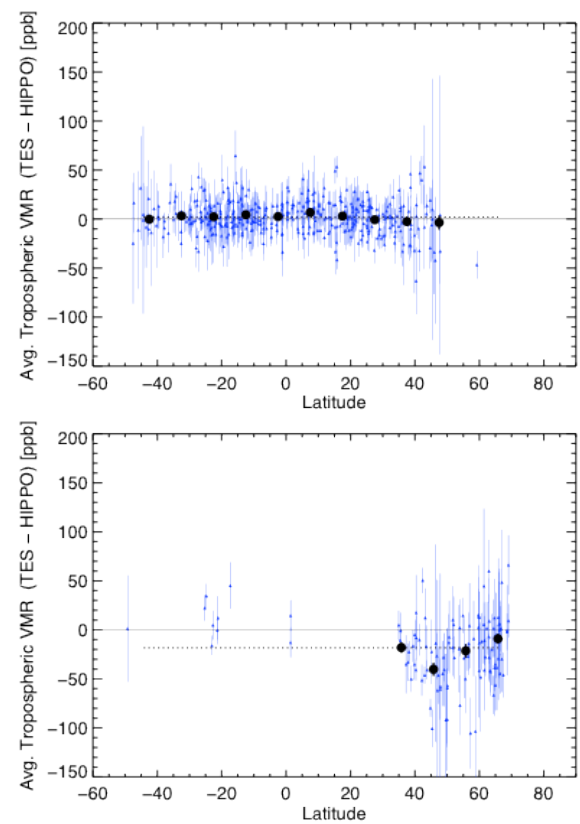

Figure 10. Latitudinal profiles of the differences between average tropospheric volume mixing ratios (VMRs) of the $\mathrm{N}_{2} \mathrm{O}-$ and global biascorrected TES $\mathrm{CH}_{4}$ retrievals and HIPPO $\mathrm{CH}_{4}$ measurements for all five HIPPO campaigns. The average tropospheric VMR is calculated as the mean of the VMRs on the TES retrieval grid between $900 \mathrm{hPa}$ and the tropopause. The left column has the results for TES Version 5 , and the right column has the results for TES Version 6. The top panel of each column shows the results for TES retrievals where the degrees of freedom for signal (DOFS) is $\geq 1.6$. The bottom panel shows the results in scenes where the DOFS is $<1.6$. The blue triangles are the differences for the individual TES retrievals, with blue lines showing the estimated retrieval error. The black circles show the mean bias for the scans binned by $10^{\circ}$ latitude, while the black error bars are the standard deviation in each bin. Circles are only plotted when at least 10 scans are in a bin.

with the 10-20 ppbv positive mean bias seen in the $\mathrm{N}_{2} \mathrm{O}$ profiles retrieved by TES.

Thus it is more likely that remaining bias is symptomatic of inadequacies in the assumption that the errors that impact the $\mathrm{N}_{2} \mathrm{O}$ retrieval impact the $\mathrm{CH}_{4}$ retrieval in a similar manner. The improvement in the retrieved $\mathrm{N}_{2} \mathrm{O}$ when the updated $\mathrm{N}_{2} \mathrm{O}$ parameters are used suggests that rather than the same systematic errors causing the positive bias in the TES retrievals of $\mathrm{CH}_{4}$ and $\mathrm{N}_{2} \mathrm{O}$, these remaining biases are primarily due to spectroscopic errors, a significant fraction of which are independent.

We note that we have demonstrated in Sect. 5 above that the $\mathrm{N}_{2} \mathrm{O}$-corrected, bias-corrected $\mathrm{TES}_{\mathrm{CH}}$ retrievals from Version 6 match the measured HIPPO profiles well for cases in which the TES retrievals have more than 1.6 DOFS, and we still recommend the use of both corrections with TES Version 6 data.

Our results suggest that further work is needed on either the $\mathrm{CH}_{4} / \mathrm{H}_{2} \mathrm{O}$ spectroscopy, or on empirical, post hoc correction approaches, before the updated $\mathrm{N}_{2} \mathrm{O}$ spectroscopy can bring improvements to the TES $\mathrm{CH}_{4}$ product.

\section{Conclusions}

We have evaluated the impact of spectroscopic updates on TES $\mathrm{CH}_{4}$ retrievals, using measured $\mathrm{CH}_{4}$ profiles from all five HIPPO campaigns, following the methods previously used in Wecht et al. (2012) to evaluate TES Version 5 (V005) products with HIPPO I and II data. We find that the updated spectroscopic parameters for $\mathrm{CH}_{4}$ and $\mathrm{H}_{2} \mathrm{O}$ in TES Version 6 result in a significant decrease of the positive bias in both the uncorrected TES $\mathrm{CH}_{4}$ retrievals and in the TES $\mathrm{CH}_{4}$ retrievals after the $\mathrm{N}_{2} \mathrm{O}$-based correction of Worden et al. (2012) is applied (while the updated a priori profiles in Version 6 have little impact). Examinations of the spectral residuals after retrievals suggest that most of the improvement in the retrieved $\mathrm{CH}_{4}$ is due to the updates in the $\mathrm{CH}_{4}$ spectroscopic parameters, rather than those of $\mathrm{H}_{2} \mathrm{O}$. For the $\mathrm{N}_{2} \mathrm{O}$-corrected TES $\mathrm{CH}_{4}$ profiles with at least 1.6 DOFS (generally between $50^{\circ} \mathrm{S}$ and $50^{\circ} \mathrm{N}$ ), the bias in the upper tropospheric representative value decreases from 56.9 to $25.7 \mathrm{ppbv}$, while the bias in the lower tropospheric representative value only increases slightly (from 27.3 to $28.4 \mathrm{ppbv}$ ). For retrievals with less than 1.6 DOFS, and thus a single-parameter RTVMR, the bias is reduced from 26.8 to 
TES Version 6
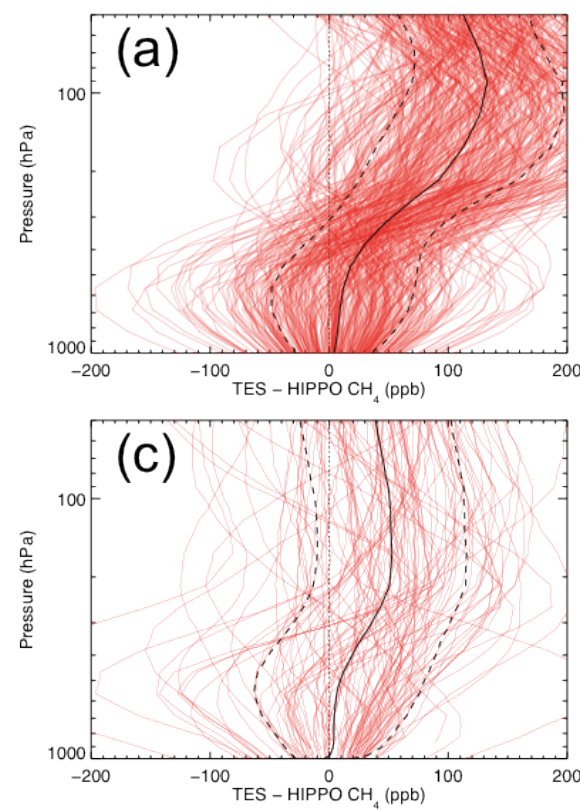

Experimental Version
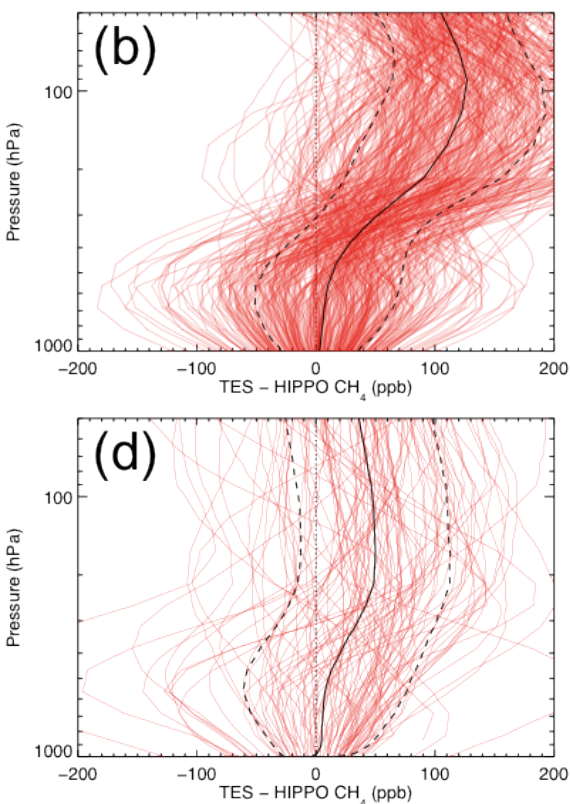

Figure 11. As in Fig. 6, but for the uncorrected $\mathrm{CH}_{4}$ retrievals from TES Version 6 and the experimental version (see Table 1).

\section{TES Version 6}
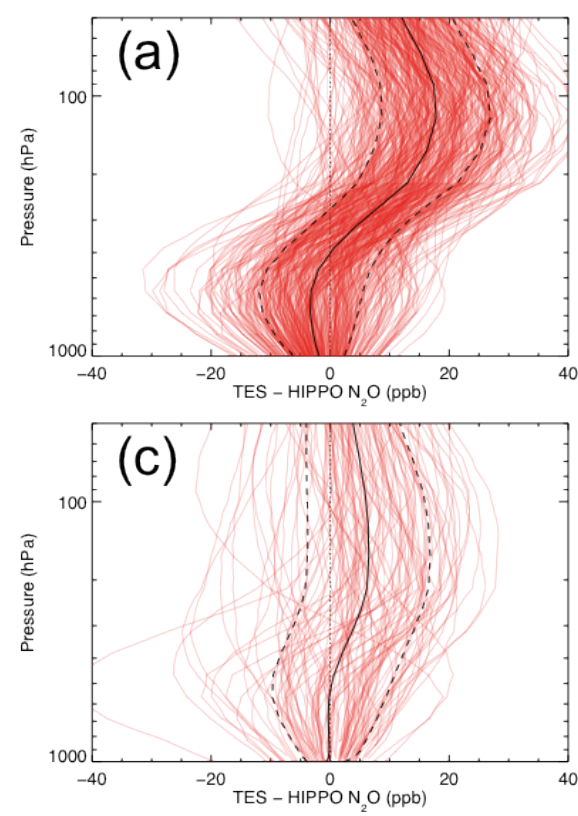

Experimental Version
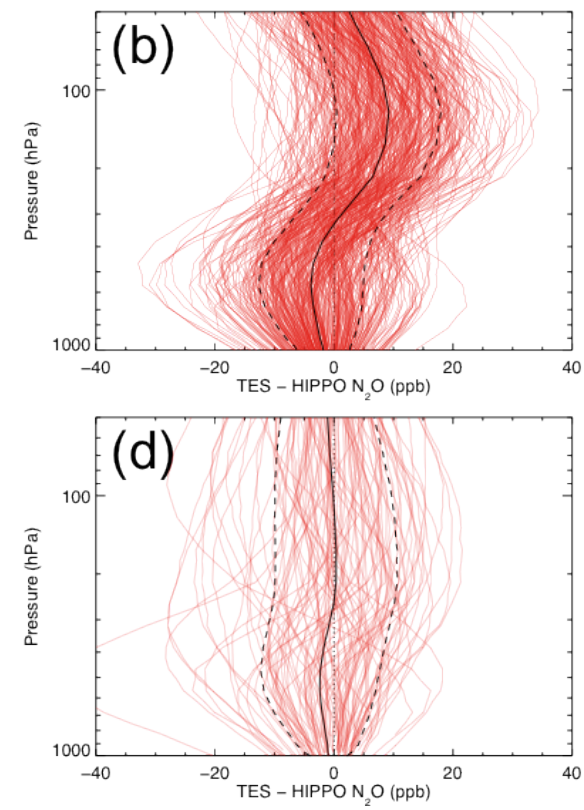

Figure 12. Differences between the retrieved TES $\mathrm{N}_{2} \mathrm{O}$ profiles and the measured HIPPO $\mathrm{N}_{2} \mathrm{O}$ profiles. The red lines are for each TES spectra analyzed, while the black solid line shows the mean differences and the black dashed lines show the standard deviation. (a) TES Version $5 \mathrm{~N}_{2} \mathrm{O}$ for TES $\mathrm{CH}_{4}$ retrievals with DOFS $\geq 1$.6. (b) TES Version $6 \mathrm{~N}_{2} \mathrm{O}$ retrievals with DOFS $\geq 1.6$. (c) TES Version $5 \mathrm{~N}_{2} \mathrm{O}$ for TES $\mathrm{CH}_{4}$ retrievals with DOFS $<$ 1.6. (d) TES Version $6 \mathrm{~N}_{2} \mathrm{O}$ for $\mathrm{TES}_{\mathrm{CH}_{4}}$ retrievals with DOFS $<1.6$. 


\section{TES Version 5}
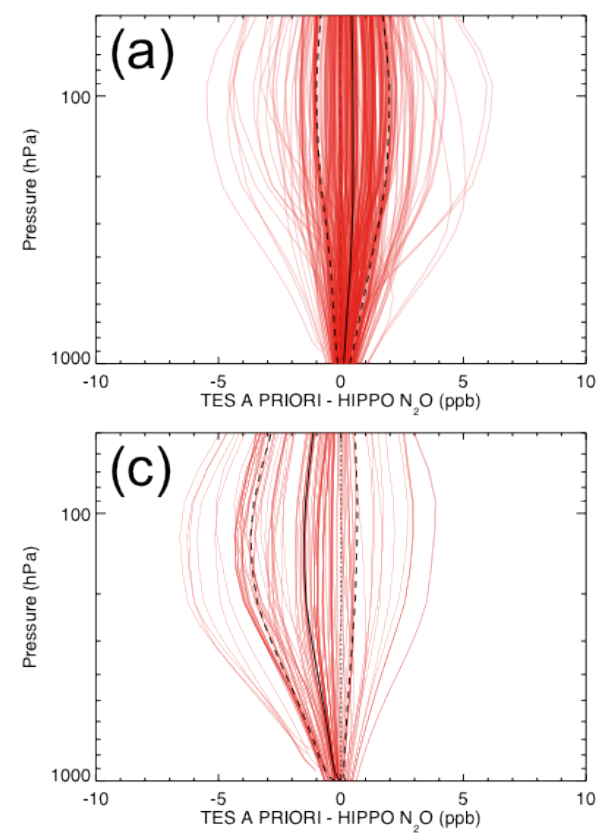

TES Version 6
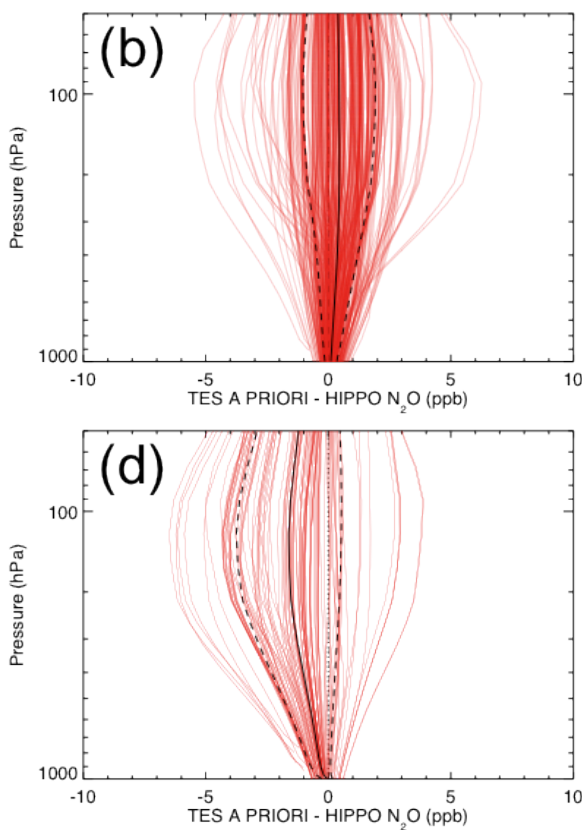

Figure 13. Differences between the TES $\mathrm{N}_{2} \mathrm{O}$ a priori profiles and the measured HIPPO $\mathrm{N}_{2} \mathrm{O}$ profiles. The red lines are for each TES spectra analyzed, while the black solid line shows the mean differences and the black dashed lines show the standard deviation. (a) TES Version 5 $\mathrm{N}_{2} \mathrm{O}$ a priori for TES $\mathrm{CH}_{4}$ retrievals with DOFS $\geq 1.6$ (generally between $50^{\circ} \mathrm{S}$ and $50^{\circ} \mathrm{N}$ ). (b) TES Version $6 \mathrm{~N}_{2} \mathrm{O}$ a priori for TES CH retrievals with DOFS $\geq 1$.6. (c) TES Version $5 \mathrm{~N}_{2} \mathrm{O}$ a priori for $\mathrm{TES}_{\mathrm{CH}_{4}}$ retrievals with DOFS $<1.6$ (generally between $30^{\circ} \mathrm{N}$ and $70^{\circ} \mathrm{N}$ ). (d) TES Version $6 \mathrm{~N}_{2} \mathrm{O}$ a priori for TES $\mathrm{CH}_{4}$ retrievals with DOFS $<1.6$.

$4.8 \mathrm{ppbv}$. There is little evidence of a latitudinal dependence of the biases for either TES Version 5 or Version 6. In addition, the mean bias in the $\mathrm{N}_{2} \mathrm{O}$-corrected $\mathrm{CH}_{4}$ is reasonably constant with height for Version 6, although errors in individual scans show a characteristic "S" or "inverted S" shape with height. An additional global bias correction can be applied to remove the remaining bias in $\mathrm{TES} \mathrm{CH}_{4}$ retrievals with at least 1.6 DOFS. We thus conclude that the TES Version $6 \mathrm{CH}_{4}$ is a significant improvement on TES Version 5.

We also examined the impact of adding the updated $\mathrm{N}_{2} \mathrm{O}$ spectroscopic parameters from HITRAN 2008 to the TES Version 6 retrievals. These updated $\mathrm{N}_{2} \mathrm{O}$ parameters have little impact on the uncorrected $\mathrm{CH}_{4}$ retrieved by TES and do reduce the positive bias in the TES retrievals of $\mathrm{N}_{2} \mathrm{O}$. For TES this reduces the strength of the $\mathrm{N}_{2} \mathrm{O}$-based correction for the $\mathrm{CH}_{4}$ retrieval bias, and would result in a more biased $\mathrm{CH}_{4}$ product if corrected in a similar fashion as in TES Versions 5 and 6. Further work is needed, either on the $\mathrm{CH}_{4} / \mathrm{H}_{2} \mathrm{O}$ spectroscopy or on a new post hoc correction methodology, in order to allow the inclusion of the updated $\mathrm{N}_{2} \mathrm{O}$ spectroscopic parameters to bring improvements to the TES retrieval $\mathrm{CH}_{4}$ product. Nonetheless, we conclude that in terms of $\mathrm{N}_{2} \mathrm{O}$ retrievals, the HITRAN $2008 \mathrm{~N}_{2} \mathrm{O}$ parameters are an improvement over the HITRAN 2000 list.
Acknowledgements. This research was supported by the US National Science Foundation under the HIPPO Program, and under NASA contracts to Atmospheric and Environmental Research (AER) and the Jet Propulsion Laboratory, California Institute of Technology (JPL). We thank Eric A. Kort of the University of Michigan and all the other members of the HIPPO Science Team for their assistance with the data.

Edited by: G. Stiller

\section{References}

Alvarado, M. J., Cady-Pereira, K. E., Xiao, Y., Millet, D. B., and Payne, V. H.: Emission Ratios for Ammonia and Formic Acid and Observations of Peroxy Acetyl Nitrate (PAN) in Biomass Burning Smoke As Seen By the Tropospheric Emission Spectrometer (TES), Atmosphere, 2, 633-654, doi:10.3390/atmos2040633, 2011.

Alvarado, M. J., Payne, V. H., Mlawer, E. J., Uymin, G., Shephard, M. W., Cady-Pereira, K. E., Delamere, J. S., and Moncet, J.L.: Performance of the Line-By-Line Radiative Transfer Model (LBLRTM) for temperature, water vapor, and trace gas retrievals: recent updates evaluated with IASI case studies, Atmos. Chem. Phys., 13, 6687-6711, doi:10.5194/acp-13-6687-2013, 2013.

Anderson, G. P., Clough, S. A., Kneizys, F. X., Chetwynd, J. H., and Shettle, E. P.: AFGL Atmospheric Constituent Profiles (0- 
120 km), Technical Report AFGL-TR-86-0110, Air Force Geophysics Laboratory, Hanscom AFB, MA, USA, 43 pp., 1986.

Beer, R., Glavich, T. A., and Rider, D. M.: Tropospheric emission spectrometer for the Earth Observing System's Aura satellite, Appl. Optics, 40, 2356-2367, 2001.

Bergamaschi, P., Frankenberg, C., Meirink, J. F., Krol, M., Dentener, F., Wagner, T., Platt, U., Kaplan, J. O., Korner, S., Heimann, M., Dlugokencky, E. J., and Goede A.: Satellite chartography of atmospheric methane from SCIAMACHY on board ENVISAT: 2. Evaluation based on inverse model simulations, J. Geophys. Res., 112, D02304, doi:10.1029/2006JD007268, 2007.

Bergamaschi, P., Frankenberg, C., Meirink, J. F., Krol, M., Villani, M. G., Houweling, S., Dentener, F., Dlugokencky, E. J., Miller, J. B., Gatti, L. V., Engel, A., and Levin I.: Inverse modeling of global and regional $\mathrm{CH} 4$ emissions using SCIAMACHY satellite retrievals, J. Geophys. Res., 114, D22301, doi:10.1029/2009JD012287, 2009.

Bowman, K. W., Rodgers, C. D., Sund-Kulawik, S., Worden, J., Sarkissian, E., Osterman, G., Steck, T., Luo, M., Eldering, A., Shephard, M. W., Worden, H., Clough, S. A., Brown, P. D., Rinsland, C. P., Lampel, M., Gunson, M., and Beer, R.: Tropospheric emission spectrometer: Retrieval method and error analysis, IEEE Geosci. Remote Sens., 44, 1297-1307, doi:10.1109/TGRS.2006.871234, 2006.

Brasseur, G. P., Hauglustaine, D. A., Walters, S., Rasch, P. J., Müller, J.-F., Granier, C., and Tie, X. X.: MOZART, a global chemical transport model for ozone and related chemical tracers: 1. Model description, J. Geophys. Res., 103, 28265-28289, doi:10.1029/98JD02397, 1998.

Cady-Pereira, K. E., Shephard, M. W., Millet, D. B., Luo, M., Wells, K. C., Xiao, Y., Payne, V. H., and Worden, J.: Methanol from TES global observations: retrieval algorithm and seasonal and spatial variability, Atmos. Chem. Phys., 12, 8189-8203, doi:10.5194/acp-12-8189-2012, 2012.

Cady-Pereira, K. E., Chaliyakunnel, S., Shephard, M. W., Millet, D. B., Luo, M., and Wells, K. C.: HCOOH measurements from space: TES retrieval algorithm and observed global distribution, Atmos. Meas. Tech., 7, 2297-2311, doi:10.5194/amt-72297-2014, 2014.

Ciais, P., Sabine, C., Bala, G., Bopp, L., Brovkin, L. V., Canadell, J., Chhabra, A., DeFries, R., Galloway, J., Heimann, M., Jones, C., Le Quéré, C., Myneni, R. B., Pia, S., and Thornton, P.: Carbon and Other Biogeochemical Cycles, in: Climate Change 2013: The Physical Science Basis, Contribution of Working Group I to the Fifth Assessment Report of the Intergovernmental Panel on Climate Change, edited by: Stocker, T. F., Qin, D., Plattner, G.K., Tignor, M., Allen, S. K., Boschung, J., Nauels, A., Xia, Y., Bex, V., and Midgley, P. M., Cambridge University Press, Cambridge, United Kingdom and New York, NY, USA, 2013.

Clough, S. A., Shephard, M. W., Mlawer, E. J., Delamere, J. S., Iacono, M. J., Cady-Pereira, K., Boukabara, S., and Brown, R. D.: Atmospheric radiative transfer modeling: a summary of the AER codes, J. Quant. Spectrosc. Radiat. T., 91, 233-244, 2005.

Clough, S. A., Shephard, M. W., Worden, J., Brown, P. D., Worden, H. M., Luo, M., Rodgers, C. D., Rinsland, C. P., Goldman, A., Brown, L., Sund-Kulawik, S., Eldering, A., Lampel, M. C., Osterman, G., Beer, R., Bowman, K., Cady-Pereira, K. E., and Mlawer, E. J.: Forward Model and Jacobians for Tropospheric
Emission Spectrometer Retrievals, IEEE Trans. Geosci. Remote Sens., 44, 1308-1323, 2006.

Connor, T. C., Shephard, M. W., Payne, V. H., Cady-Pereira, K. E., Kulawik, S. S., Luo, M., Osterman, G., and Lampel, M.: Long-term stability of TES satellite radiance measurements, Atmos. Meas. Tech., 4, 1481-1490, doi:10.5194/amt-4-1481-2011, 2011.

Coudert, L. H., Wagner, G., Birk, M., Baranov, Yu I., Lafferty, W. J., and Flaud, J.-M.: The $\mathrm{H}_{2}^{16} \mathrm{O}$ molecule: Line position and line intensity analyses up to the second triad, J. Mol. Spectrosc., 251, 339, doi:10.1016/j.jms.2008.03.021, 2008.

Crevoisier, C., Nobileau, D., Fiore, A. M., Armante, R., Chédin, A., and Scott, N. A.: Tropospheric methane in the tropics - first year from IASI hyperspectral infrared observations, Atmos. Chem. Phys., 9, 6337-6350, doi:10.5194/acp-9-6337-2009, 2009.

Crevoisier, C., Nobileau, D., Armante, R., Crépeau, L., Machida, T., Sawa, Y., Matsueda, H., Schuck, T., Thonat, T., Pernin, J., Scott, N. A., and Chédin, A.: The 2007-2011 evolution of tropical methane in the mid-troposphere as seen from space by MetOpA/IASI, Atmos. Chem. Phys., 13, 4279-4289, doi:10.5194/acp13-4279-2013, 2013.

Dlugokencky, E. J., Nisbet, E. G., Fisher, R., and Lowry, D.: Global atmospheric methane: budget, changes and dangers, Philos. T. Roy. Soc. A, 369, 2058-2072, doi:10.1098/rsta.2010.0341, 2011.

Emmons, L. K., Walters, S., Hess, P. G., Lamarque, J.-F., Pfister, G. G., Fillmore, D., Granier, C., Guenther, A., Kinnison, D., Laepple, T., Orlando, J., Tie, X., Tyndall, G., Wiedinmyer, C., Baughcum, S. L., and Kloster, S.: Description and evaluation of the Model for Ozone and Related chemical Tracers, version 4 (MOZART-4), Geosci. Model Dev., 3, 43-67, doi:10.5194/gmd3-43-2010, 2010.

Frankenberg, C., Meirink, J. F., van Weele, M., Platt, U., and Wagner, T.: Assessing Methane Emissions from Global Space-Borne Observations, Science, 308, 1010-1014, doi:10.1126/science.1106644, 2005.

Frankenberg, C., Aben, I., Bergamaschi, P., Dlugokencky, E. J., van Hees, R., Houweling, S., van der Meer, P., Snel, R., and Tol, P.: Global column-averaged methane mixing ratios from 2003 to 2009 as derived from SCIAMACHY: Trends and variability, J. Geophys. Res., 116, D04302, doi:10.1029/2010JD014849, 2011.

Herbin, H., Labonnote, L. C., and Dubuisson, P.: Multispectral information from TANSO-FTS instrument - Part 1: Application to greenhouse gases $\left(\mathrm{CO}_{2}\right.$ and $\left.\mathrm{CH}_{4}\right)$ in clear sky conditions, Atmos. Meas. Tech., 6, 3301-3311, doi:10.5194/amt-6-3301-2013, 2013.

Kort, E. A., Patra, P. K., Ishijima, K., Daube, B. C., Jimenez, R., Elkins, J., Hurst, D., Moore, F. L., Sweeney, C., and Wofsy, S. C.: Tropospheric distribution and variability of N2O: Evidence for strong tropical emissions, Geophys. Res. Lett., 38, L15806, doi:10.1029/2011GL047612, 2011.

Kuai, L., Worden, J., Kulawik, S. S., Montzka, S. A., and Liu, J.: Characterization of Aura TES carbonyl sulfide retrievals over ocean, Atmos. Meas. Tech., 7, 163-172, doi:10.5194/amt-7-1632014, 2014.

Kulawik, S. S., Osterman, G., Jones, D. B. A., and Bowman, K. W.: Calculation of altitude-dependent Tikhonov constraints for TES nadir retrievals, IEEE T. Geosci. Remote, 44, 1334-1342, 2006.

Kulawik, S. S., Jones, D. B. A., Nassar, R., Irion, F. W., Worden, J. R., Bowman, K. W., Machida, T., Matsueda, H., Sawa, 
Y., Biraud, S. C., Fischer, M. L., and Jacobson, A. R.: Characterization of Tropospheric Emission Spectrometer (TES) $\mathrm{CO}_{2}$ for carbon cycle science, Atmos. Chem. Phys., 10, 5601-5623, doi:10.5194/acp-10-5601-2010, 2010.

Kulawik, S. S., Worden, J. R., Wofsy, S. C., Biraud, S. C., Nassar, R., Jones, D. B. A., Olsen, E. T., Jimenez, R., Park, S., Santoni, G. W., Daube, B. C., Pittman, J. V., Stephens, B. B., Kort, E. A., Osterman, G. B., and TES team: Comparison of improved Aura Tropospheric Emission Spectrometer CO2 with HIPPO and SGP aircraft profile measurements, Atmos. Chem. Phys., 13, 32053225, doi:10.5194/acp-13-3205-2013, 2013.

Lamouroux, J., Tran, H, Laraia, A. L., Gamache, R. R., Rothman, L. S., Gordon, I. E., and Hartmann, J.-M.: Updated database plus software for line-mixing in $\mathrm{CO}_{2}$ infrared spectra and their test using laboratory spectra in the $1.5-2.3 \mu \mathrm{m}$ region, J. Quant. Spectrosc. Radiat. T., 111, 2321, doi:10.1016/j.jqsrt.2010.03.006, 2010.

Luo, M., Rinsland, C. P., Rodgers, C. D., Logan, J. A., Worden, H., Kulawik, S., Eldering, A., Goldman, A., Shephard, M. W., Gunson, M., and Lampel, M.: Comparison of carbon monoxide measurements by TES and MOPITT: Influence of a priori data and instrument characteristics on nadir atmospheric species retrievals, J. Geophys. Res., 112, D09303, doi:10.1029/2006JD007663, 2007.

Marsh, D. R., Mills, M. J., Kinnison, D. E., Lamarque, J. F., Calvo, N., and Polvani, L. M.: Climate Change from 1850 to 2005 Simulated in CESM1 (WACCM, J. Climate, 26, 7372-7391, 2013.

Massart, S., Agusti-Panareda, A., Aben, I., Butz, A., Chevallier, F., Crevoisier, C., Engelen, R., Frankenberg, C., and Hasekamp, O.: Assimilation of atmospheric methane products into the MACC-II system: from SCIAMACHY to TANSO and IASI, Atmos. Chem. Phys., 14, 6139-6158, doi:10.5194/acp-14-6139-2014, 2014.

Meirink, J. F., Bergamaschi, P., Frankenberg, C., D’Amelio, M. T. S., Dlugokencky, E. J., Gatti, L. V., Houweling, S., Miller, J. B., Rockmann, T., Villani, M. G., and Krol, M. C.: Four-dimensional variational data assimilation for inverse modeling of atmospheric methane emissions: Analysis of SCIAMACHY observations, J. Geophys. Res., 113, D17301, doi:10.1029/2007JD009740, 2008.

Mlawer, E. J., Payne, V. H., Moncet, J.-L., Delamere, J. S., Alvarado, M. J., and Tobin, D. D.: Development and recent evaluation of the MT_CKD model of continuum absorption, Phil. Trans. Roy. Soc. A, 370, 1-37, doi:10.1098/rsta.2011.0295, 2012.

Myhre, G., Shindell, D., Bréon, F.-M., Collins, W., Fuglestvedt, J., Huang, J., Koch, D., Lamarque, J.-F., Lee, D., Mendoza, B., Nakajima, T., Robock, A., Stephens, G., Takemura, T., and Zhang, H.: Anthropogenic and Natural Radiative Forcing, in: Climate Change 2013: The Physical Science Basis, Contribution of Working Group I to the Fifth Assessment Report of the Intergovernmental Panel on Climate Change, edited by: Stocker, T. F., Qin, D., Plattner, G.-K., Tignor, M., Allen, S. K., Boschung, J., Nauels, A., Xia, Y., Bex, V., and Midgley, P. M., Cambridge University Press, Cambridge, United Kingdom and New York, NY, USA, 2013.

Nassar, R., Logan, J. A., Worden, H. M., Megretskaia, I. A., Bowman, K. W., Osterman, G. B., Thompson, A. M., Tarasick, D. W., Austin, S., Claude, H., Dubey, M. K., Hocking, W. K., Johnson, B. J., Joseph, E., Merrill, J., Morris, G. A., Newchurch, M., Oltmans, S. J., Posny, F., Schmidlin, F. J.,
Vömel, H., Whiteman, D. N., and Witte, J. C.: Validation of Tropospheric Emission Spectrometer (TES) nadir ozone profiles using ozonesonde measurements, J. Geophys. Res., 113, D15S17, doi:10.1029/2007JD008819, 2008.

Niro, F., Jucks, K., and Hartmann, J.-M.: Spectral calculations in central and wing regions of $\mathrm{CO}_{2}$ IR bands. IV: Software and database for the computation of atmospheric spectra, J. Quant. Spectrosc. Radiat. T., 95, 469-481, 2005.

Park, M., Randel, W. J., Kinnison, D. E., Garcia, R. R., and Choi, W.: Seasonal variation of methane, water vapor, and nitrogen oxides near the tropopause: Satellite observations and model simulations, J. Geophys. Res., 109, D03302, doi:10.1029/2003JD003706, 2004.

Payne, V. H., Clough, S. A., Shephard, M. W., Nassar, R., and Logan, J. A.: Information-centered representation of retrievals with limited degrees of freedom for signal: application to methane from the Tropospheric Emission Spectrometer, J. Geophys. Res., 17, D10307, doi:10.1029/2008JD010155, 2009.

Payne, V. H., Alvarado, M. J., Cady-Pereira, K. E., Worden, J. R., Kulawik, S. S., and Fischer, E. V.: Satellite observations of peroxyacetyl nitrate from the Aura Tropospheric Emission Spectrometer, Atmos. Meas. Tech., 7, 3737-3749, doi:10.5194/amt-7-37372014, 2014.

Pinder, R. W., Walker, J. T., Bash, J. O., Cady-Pereira, K. E., Henze, D. K., Luo, M., and Shephard, M. W.: Quantifying spatial and temporal variability in atmospheric ammonia with in situ and space-based observations, Geophys. Res. Lett., 38, L04802, doi:10.1029/2010GL046146, 2011.

Razavi, A., Clerbaux, C., Wespes, C., Clarisse, L., Hurtmans, D., Payan, S., Camy-Peyret, C., and Coheur, P. F.: Characterization of methane retrievals from the IASI space-borne sounder, Atmos. Chem. Phys., 9, 7889-7899, doi:10.5194/acp-9-7889-2009, 2009.

Rienecker, M. M., Suarez, M. J., Todling, R., Bacmeister, J., Takacs, L., Liu, H.-C., Gu, W., Sienkiewicz, M., Koster, R. D., Gelaro, R., Stajner, I., and Nielsen, J. E.: The GEOS-5 Data Assimilation System - Documentation of Versions 5.0.1, 5.1.0, and 5.2.0, NASA Technical Report Series on Global Modeling and Data Assimilation, vol. 27, edited by: Suarez, M. J., NASA/TM2008-104606, 2008.

Rigby, M., Prinn, R. G., Fraser, P. J., Simmonds, P. G., Langenfelds, R. L., Huang, J., Cunnold, D. M., Steele, L. P., Krummel, P. B., Weiss, R. F., O’Doherty, S., Salameh, P. K., Wang, H. J., Harth, C. M., Mühle, J., and Porter, L. W.: Renewed growth of atmospheric methane, Geophys. Res. Lett., 35, L22805, doi:10.1029/2008GL036037, 2008.

Rinsland, C. P., Luo, M., Logan, J. A., Beer, R., Worden, H., Kulawik, S. S., Rider, D., Osterman, G., Gunson, M., Eldering, A., Goldman, A., Shephard, M., Clough, S. A., Rodgers, C., Lampel, M., and Chiou, L.: Nadir measurements of carbon monoxide distributions by the Tropospheric Emission Spectrometer instrument onboard the Aura Spacecraft: Overview of analysis approach and examples of initial results, Geophys. Res. Lett., 33, L22806, doi:10.1029/2006GL027000, 2006.

Rodgers, C. D.: Inverse Methods for Atmospheric Sounding: Theory and Practice, World Sci., Hackensack, N. J., 2000.

Rodgers, C. D. and Connor, B. J.: Intercomparison of remote sounding instruments, J. Geophys. Res., 108, 4116, doi:10.1029/2002JD002299, 2003. 
Rothman, L. S., Barbe, A., Benner, D. C., Brown, L. R., CamyPeyret, C., Carleer, M. R., Chance, K. V., Clerbaux, C., Dana, V., Devi, V. M., Fayt, A., Flaud, J-M., Gamache, R. R., Goldman, A., Jacquemart, D., Jucks, K. W., Lafferty, W. J., Mandin, J-Y., Massie, S. T., Nemtchinov, V., Newnham, D. A., Perrin, A., Rinsland, C. P., Schroeder, J., Smith, K. M., Smith, M. A. H., Tang, K., Toth, R. A., Vander Auwera, J., Varanasi, P., and Yoshino, K.: The HITRAN Molecular Spectroscopic Database: Edition of 2000 Including Updates through 2001, J. Quant. Spectrosc. Radiat. T., 82, 5-44, 2003.

Rothman, L. S., Jacquemart, D., Barbe, A., Benner, D. C., Birk, M., Brown, L. R., Carleer, M. R., Chackerian, C., Jr., Chance, K., Coudert, L. H., Dana, V., Devi, V. M., Flaud, J.-M., Gamache, R. R., Goldman, A., Hartmann, J.-M., Jucks, K. W., Maki, A. G., Mandin, J.-Y., Massie, S. T., Orphal, J., Perrin, A., Rinsland, C. P., Smith, M. A. H., Tennyson, J., Tolchenov, R. N., Toth, R. A., Vander Auwera, J., Varanasi, P., and Wagner, G.: The HITRAN 2004 molecular spectroscopic database, J. Quant. Spectrosc. Radiat. T., 96, 139-204, 2005.

Rothman, L. S., Gordon, I. E., Barbe, A., Benner, D. C., Bernath, P. F., Birk, M., Boudon, V., Brown, L. R., Campargue, A., Champion, J.-P., Chance, K., Coudert, L. H., Dana, V., Devi, V. M., Fally, S., Flaud, J.-M., Gamache, R. R., Goldman, A., Jacquemart, D., Kleiner, I., Lacome, N., Lafferty, W. J., Mandin, J.Y., Massie, S. T., Mikhailenko, S. N., Miller, C. E., MoazzenAhmadi, N., Naumenko, O. V., Nikitin, A. V., Orphal, J., Perevalov, V. I., Perrin, A., Predoi-Cross, A., Rinsland, C. P., Rotger, M., Šimečková, M., Smith, M. A. H., Sung, K., Tashkun, S. A., Tennyson, J., Toth, R. A., Vandaele, A. C., and Vander Auwera, J: The HITRAN 2008 molecular spectroscopic database, J. Quant. Spectrosc. Radiat. T., 110, 533-572, 2009.

Santoni, G. W., Daube, B. C., Kort, E. A., Jiménez, R., Park, S., Pittman, J. V., Gottlieb, E., Xiang, B., Zahniser, M. S., Nelson, D. D., McManus, J. B., Peischl, J., Ryerson, T. B., Holloway, J. S., Andrews, A. E., Sweeney, C., Hall, B., Hintsa, E. J., Moore, F. L., Elkins, J. W., Hurst, D. F., Stephens, B. B., Bent, J., and Wofsy, S. C.: Evaluation of the airborne quantum cascade laser spectrometer (QCLS) measurements of the carbon and greenhouse gas suite $-\mathrm{CO}_{2}, \mathrm{CH}_{4}, \mathrm{~N}_{2} \mathrm{O}$, and $\mathrm{CO}$ - during the CalNex and HIPPO campaigns, Atmos. Meas. Tech., 7, 1509-1526, doi:10.5194/amt-7-1509-2014, 2014.

Shephard, M. W., Clough, S. A., Payne, V. H., Smith, W. L., Kireev, S., and Cady-Pereira, K. E.: Performance of the line-by-line radiative transfer model (LBLRTM) for temperature and species retrievals: IASI case studies from JAIVEx, Atmos. Chem. Phys., 9, 7397-7417, doi:10.5194/acp-9-7397-2009, 2009.

Shephard, M. W., Cady-Pereira, K. E., Luo, M., Henze, D. K., Pinder, R. W., Walker, J. T., Rinsland, C. P., Bash, J. O., Zhu, L., Payne, V. H., and Clarisse, L.: TES ammonia retrieval strategy and global observations of the spatial and seasonal variability of ammonia, Atmos. Chem. Phys., 11, 10743-10763, doi:10.5194/acp-11-10743-2011, 2011.

Tran, H., Flaud, J.-M., Gabard, T., Hase, F., Von Clarmann, T., Camy-Peyret, C., Payan, S., and Hartmann, J.-M.: Model, Software and database for line-mixing effects in the $\mathrm{v}_{3}$ and $\mathrm{v}_{4}$ bands of $\mathrm{CH}_{4}$ and tests using laboratory and planetary measurements. I. $\mathrm{N}_{2}$ (and air) broadening and the Earth atmosphere, J. Quant. Spectrosc. Radiat. T., 101, 284-305, 2006.
Wecht, K. J., Jacob, D. J., Wofsy, S. C., Kort, E. A., Worden, J. R., Kulawik, S. S., Henze, D. K., Kopacz, M., and Payne, V. H.: Validation of TES methane with HIPPO aircraft observations: implications for inverse modeling of methane sources, Atmos. Chem. Phys., 12, 1823-1832, doi:10.5194/acp-12-1823-2012, 2012.

Weiss, R. F. and Prinn, R. G.: Quantifying greenhouse gas emissions from anthropogenic measurements: a critical reality check for climate legislation, Phil. Trans. R. Soc. A, 369, 1925-1942, doi:10.1098/rsta.2011.0006, 2011.

Wells, K. C., Millet, D. B., Hu, L., Cady-Pereira, K. E., Xiao, Y., Shephard, M. W., Clerbaux, C. L., Clarisse, L., Coheur, P.F., Apel, E. C., de Gouw, J., Warneke, C., Singh, H. B., Goldstein, A. H., and Sive, B. C.: Tropospheric methanol observations from space: retrieval evaluation and constraints on the seasonality of biogenic emissions, Atmos. Chem. Phys., 12, 5897-5912, doi:10.5194/acp-12-5897-2012, 2012.

Wofsy, S. C. and the HIPPO Science Team and Cooperating Modellers and Satellite Teams: HIAPER Pole-to-Pole Observations (HIPPO): fine-grained, global-scale measurements of climatically important atmospheric gases and aerosols, Philosoph. Trans. Roy. Soc. A: Mathematical, Physical and Engineering Sciences, 369, 2073-2086, doi:10.1098/rsta.2010.0313, 2011.

Wofsy, S. C., Daube, B. C., Jimenez, R., Kort, E., Pittman, J. V., Park, S., Commane, R., Xiang, B., Santoni, G., Jacob, D., Fisher, J., Pickett-Heaps, C., Wang, H., Wecht, K., Wang, Q.-Q., Stephens, B. B., Shertz, S., Watt, A. S., Romashkin, P., Campos, T., Haggerty, J., Cooper, W. A., Rogers, D., Beaton, S., Hendershot, R., Elkins, J. W., Fahey, D. W., Gao, R. S., Moore, F., Montzka, S. A., Schwarz, J. P., Perring, A. E., Hurst, D., Miller, B. R., Sweeney, C., Oltmans, S., Nance, D., Hintsa, E., Dutton, G., Watts, L. A., Spackman, J. R., Rosenlof, K. H., Ray, E. A., Hall, B., Zondlo, M. A., Diao, M., Keeling, R., Bent, J., Atlas, E. L., Lueb, R., and Mahoney, M. J.: HIPPO Merged 10-second Meteorology, Atmospheric Chemistry, Aerosol Data (R_20121129),Carbon Dioxide Information Analysis Center, Oak Ridge National Laboratory, Oak Ridge, Tennessee, USA, doi:10.3334/CDIAC/hippo_010 (Release 20121129), 2012.

Worden, H. M., Logan, J. A., Worden, J. R., Beer, R., Bowman, K., Clough, S. A., Eldering, A., Fisher, B. M., Gunson, M. R., Herman, R. L., Kulawik, S. S., Lampel, M. C., Luo, M., Megretskaia, I. A., Osterman, G. B., and Shephard, M. W.: Comparisons of Tropospheric Emission Spectrometer (TES) ozone profiles to ozonesondes: methods and initial results, J. Geophys. Res., 112, D03309, doi:10.1029/2006JD007258, 2007.

Worden, J., Noone, D., Galewsky, J., Bailey, A., Bowman, K., Brown, D., Hurley, J., Kulawik, S., Lee, J., and Strong, M.: Estimate of bias in Aura TES $\mathrm{HDO} / \mathrm{H}_{2} \mathrm{O}$ profiles from comparison of TES and in situ $\mathrm{HDO} / \mathrm{H}_{2} \mathrm{O}$ measurements at the Mauna Loa observatory, Atmos. Chem. Phys., 11, 4491-4503, doi:10.5194/acp-11-4491-2011, 2011.

Worden, J., Kulawik, S., Frankenberg, C., Payne, V., Bowman, K., Cady-Peirara, K., Wecht, K., Lee, J.-E., and Noone, D.: Profiles of $\mathrm{CH}_{4}, \mathrm{HDO}, \mathrm{H}_{2} \mathrm{O}$, and $\mathrm{N}_{2} \mathrm{O}$ with improved lower tropospheric vertical resolution from Aura TES radiances, Atmos. Meas. Tech., 5, 397-411, doi:10.5194/amt-5-397-2012, 2012.

Worden, J., Jiang, Z., Jones, D. B. A., Alvarado, M., Bowman, K., Frankenberg, C., Kort, E. A., Kulawik, S. S., Lee, M., Liu, J., Payne, V., Wecht, K., and Worden, H.: El Niño, the 2006 Indone- 
sian peat fires, and the distribution of atmospheric methane, Geophys. Res. Lett., 40, 4938-4943, doi:10.1002/grl.50937, 2013a.

Worden, J., Wecht, K., Frankenberg, C., Alvarado, M., Bowman, K., Kort, E., Kulawik, S., Lee, M., Payne, V., and Worden, H.: $\mathrm{CH}_{4}$ and $\mathrm{CO}$ distributions over tropical fires during October 2006 as observed by the Aura TES satellite instrument and modeled by GEOS-Chem, Atmos. Chem. Phys., 13, 3679-3692, doi:10.5194/acp-13-3679-2013, 2013b.

Xiong, X., Barnet, C., Maddy, E., Sweeney, C., Liu, X., Zhou, L., and Goldberg, M.: Characterization and validation of methane products from the Atmospheric Infrared Sounder (AIRS), J. Geophys. Res., 113, G00A01, doi:10.1029/2007JG000500, 2008.
Xiong, X., Houweling, S., Wei, J., Maddy, E., Sun, F., and Barnet, C.: Methane plume over south Asia during the monsoon season: satellite observation and model simulation, Atmos. Chem. Phys., 9, 783-794, doi:10.5194/acp-9-783-2009, 2009.

Xiong, X., Barnet, C. D., Zhuang, Q., Machida, T., Sweeney, C., and Patra, P. K.: Mid-upper tropospheric methane in the high Northern Hemisphere: Spaceborne observations by AIRS, aircraft measurements, and model simulations, J. Geophys. Res., 115, D19309, doi:10.1029/2009JD013796, 2010.

Zhu, L., Henze, D. K., Cady-Pereira, K. E., Shephard, M. W., Luo, M., Pinder, R. W., Bash, J. O., and Jeong, G.-R.: Constraining U.S. ammonia emissions using TES remote sensing observations and the GEOS-Chem adjoint model, J. Geophys. Res. Atmos., 118, 3355-3368, doi:10.1002/jgrd.50166, 2013. 